\title{
Creative Functionalized Bricks with Embedded Intelligence (FBEI) For Research-Oriented Provocative STEM and Workforce Learning
}

\author{
Dean M. Aslam \\ Electrical and Computer Engineering, Michigan State University, E. Lansing. MI 48824
}

\begin{abstract}
Creative Functionalized Bricks with Embedded Intelligence (FBEI), using custom-made LEGO-compatible bricks containing electronic circuits \& sensors based on new micro \& nano technologies, spark the interest of learners with different backgrounds and preparation levels from kindergarten to Ph.D. FBEI modules are based on a concept called TASEM (technology assisted science, engineering and mathematics) developed during 2000 - 2010. Doctoral students, involved in cutting-edge micro and nano research, interacted with K-12 students and teachers to develop TASEM. TASEM led to unique FBEIs covering a large number of learning areas including energy, power sources, math, Si crystals, computer switches, sensors and miniaturization, micro and nano concepts, technology assisted dancing, psychology, cognitive training, cancer education, microsystem fabrication, system integration, biomedical, and computer science. By allowing user-designs, FBEIs focus on research-oriented and entrepreneurial learning. Over 100 FBEI learning modules were developed benefiting over 2,500 learners nationally and globally.
\end{abstract}

Keywords: K-12 modules, micro and nano technologies, STEM education.

\section{INTRODUCTION}

School science using real-world problems [1][2] has led to inquiry-based studies [3][4][5][6] and design-based science [7][8][9][10][11]. The Technology-Assisted Science, Engineering, and Mathematics (TASEM) developed to spark multi- and trans-disciplinary interest [12][13][14] uses custom-made LEGO-compatible bricks containing electronic circuits \& sensors based on new micro \& nano technologies. TASEM, sparking interest of learners with different backgrounds and preparation levels from kindergarten to Ph.D leading to entrepreneurial research-oriented learning, has resulted in creative and provocative Functionalized Bricks with Embedded Intelligence (FBEI) suitable for K-16 education allowing user-designs and link to latest research. Over 100 FBEI learning modules, benefiting over 2,500 learners nationally and globally, benefit from latest doctoral research [15] in Wireless Integrated Micro Systems (WIMS).

This paper provides details of FBEIs and their creative approach. Most of the modules reported in this paper are unique and provocative. As the FBEIs involve extremely simple to extremely complex multidisciplinary engineering/science learning, they have become very popular locally and internationally to promote engineering education and research at all levels of K through Ph.D. (KPD) and workforce training.

\section{Overview}

Fig. 1 shows an overview of unique FBEI modules. There is no other such study addressing so many aspects of learning. Here are some examples:

- Gear train to explain micro and nano.

- Mind-controlled LEGO robot.

- Nano and micro fabrication modules. 
- LEGO models of neuron, neural probe, MOS technology,

\section{EXAMPLES OF FNEI/FBEIS: Over 100} modules have been developed

(a) Motion, Energy \& Batteries, Math, Si Crystal

(b) Computer Switches,

(c) Sensors and Miniaturization,

(d) Nano Concepts,

(e) Micro, Nano and Microsystems Fabrication,

(f) System Integration and

(g) Trans-disciplinary Topics (related to Technology Assisted Dancing, Psychology, Cognitive-Training and Cancer).

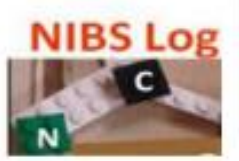

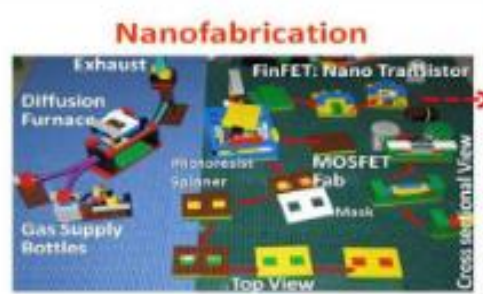

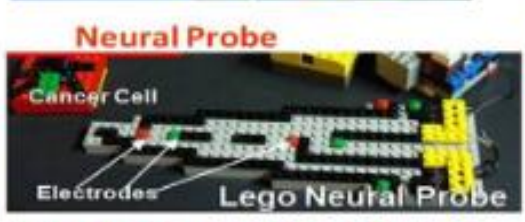

Mind-Controlled Robot

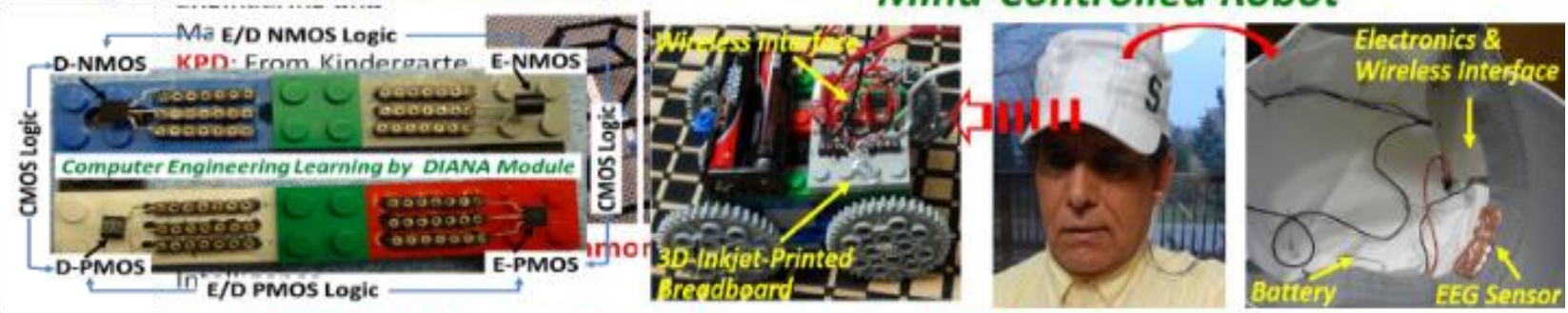

Lego Gear Train Demonstrating Macro, Micro and Nano Dimensions

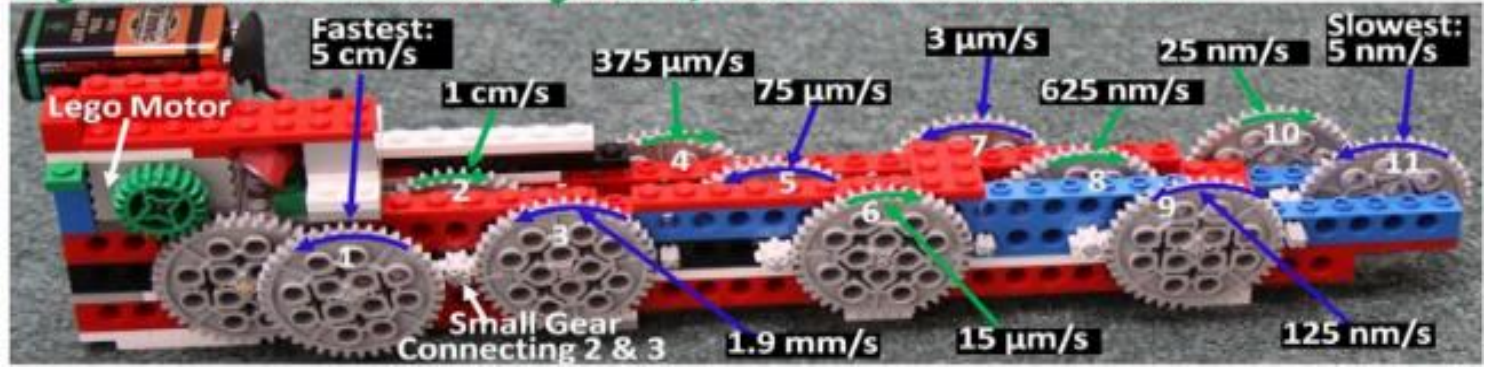

Fig. 1 Overview of FBEI modules.

\section{FBEI Modules}

Children Interested in Technology: Children ages 2- 7 show interest in technology. Such sessions, conducted in a group of approximately of 5 children in the presence of at least one of the parents in the basement of author's house, provided information about children's interest and approach in technology learning. Soap bubbles' skin is in the range of $100 \mathrm{~nm}$. An interesting aspect of bubbles is thinning of their skin leading to color change before they burst. Children like bubbles as obvious from the face of a two-year old shown in Fig. 2(a). How fast a bubble bursts depends on humidity level in the atmosphere. A 4-year old plays with motor as a generator (b) and a 7-year old demonstrates his invention in an industrial fund-raising event organized by Ardesta (c).

Low-cost modules (Fig. 3): A simple gear train built to demonstrate gear ratio as shown Fig. 3(a). A 50 cents motor is integrated with LEGO pieces, an LED and a belt (b) to turn the motor manually using it as a generator of power turning on an LED. A LEGO car powered by a motor used as generator (c). Energy storage demonstrated by storing energy in a $0.5 \mathrm{~F}(\mathrm{e})$ and $1 \mathrm{~F}$ capacitors with built-in protection circuits. A Zener diode used in the protection circuit keeps the polarity applied to the capacitor same in magnitude and polarity irrespective of clockwise or anti-clockwise direction of LEGO motor. 
Vol. 9, Issue 6, June 2020

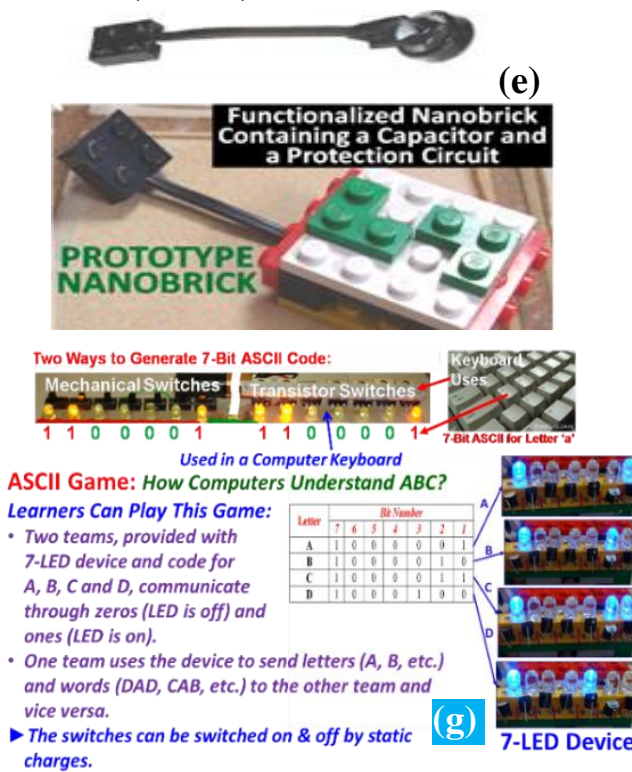

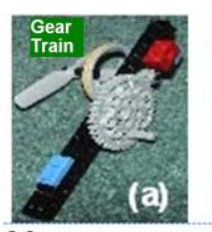
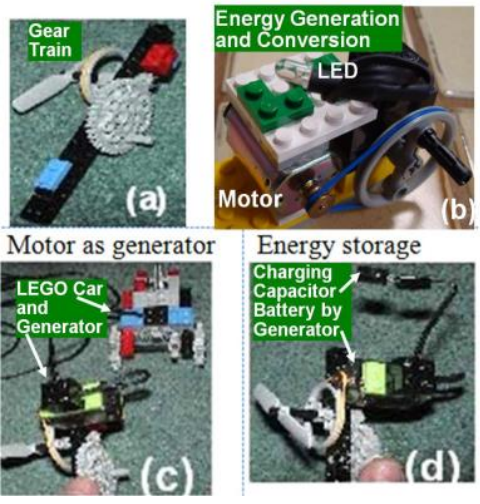

Energy storage

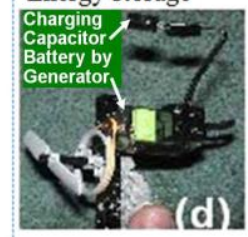

(f)

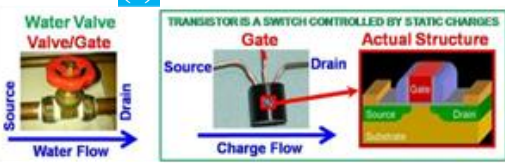

Fig. 3 Low cost learning modules; electromechanical $(a-e)$ and computer switches $(f-g)$.

During one of the summer camps, a third grader, Conrad, was charging a $1 \mathrm{~F}$ capacitor and then using it to run a LEGO car. When the author asked Conrad why he liked what he was doing, he replied, "I have the full control of what I am doing and my parents cannot tell me that I am using batteries that cost money".

Computer Switches and Microsystems:

Computer switches, switchable by static charges, are part of computer logic, Microsystems and much more. As shown in Fig. 3(f), similar to a water valve, a computer switch has a gate (valve), source and drain with gate controlling flow of charge. Fig. 3 (g), using the above mentioned parent-children groups, explains the function of a computer keyboard using computer switches. For example, two groups of children communicated through seven computer-switches without speaking. They used words such as dad, cab, bad, add, etc. Such creative learning sessions held in author's house basement for several weeks were very successful.

While micro and nano switches are crucial part of Microsystems as seen in Fig. 4, this paper describes these using LEGOs. Fig. 5 (a-c) shows a simplified microchip using components made using LEGOs. A real-world Microsystem, as shown in Fig. 4, consists of a large number of components (a). Two examples, Fig. 4 (b \& c), of innovative Microsystems

(a) System Integration for MEMS/MICROSYSTEMS
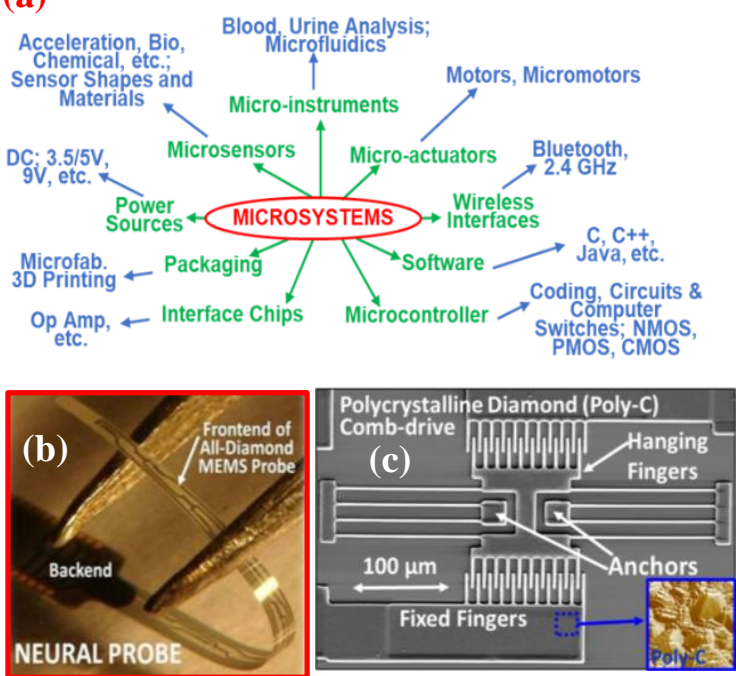

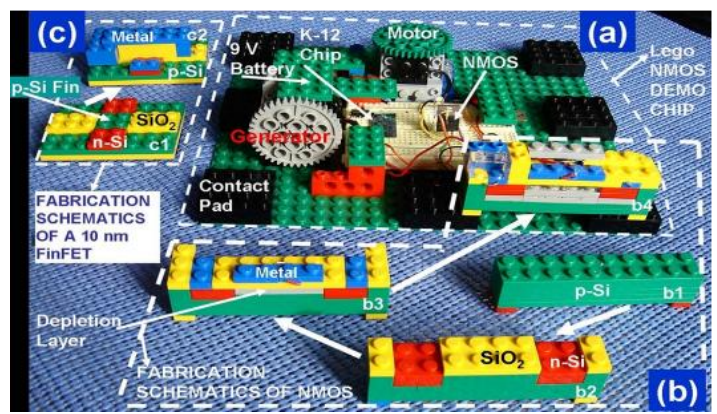

A LEGO Model of Microsystems/MEMS K-12 Chip: Micro \& Nano Computer Switches, Fabrication, Sensors \& Actuators, Power Sources, Functional Modules of NMOS and FinFET, etc.

Fig. 5 Computer switch demos using LEGOs.

Fig. 4 State of the art

are a neural probe [16] and an Radio Frequency (RF) resonator [17]. Interestingly, if the thickness of polycrystalline diamond is less than $20 \mu \mathrm{m}$, it becomes flexible as seen in Fig. 4(b). The author's research group became first to demonstrate Single-Material MEMS (SMEMS) using polycrystalline chemical vapor deposited diamond [18]. 
LEGOs: Used to Explain Resist Spinners and Plasma Oxidation Processes (Furnace Exhaust and Dispenser Nozzles for the Spinner are also Shown)

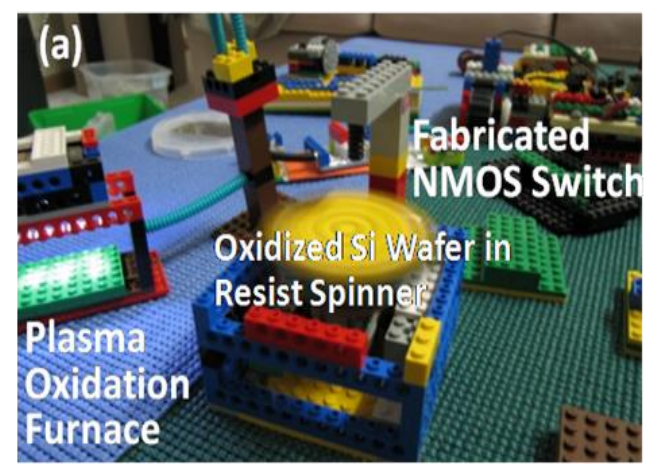

Fig. 6 Micro and nano fabrication of LEGO-based functional MOS devices.

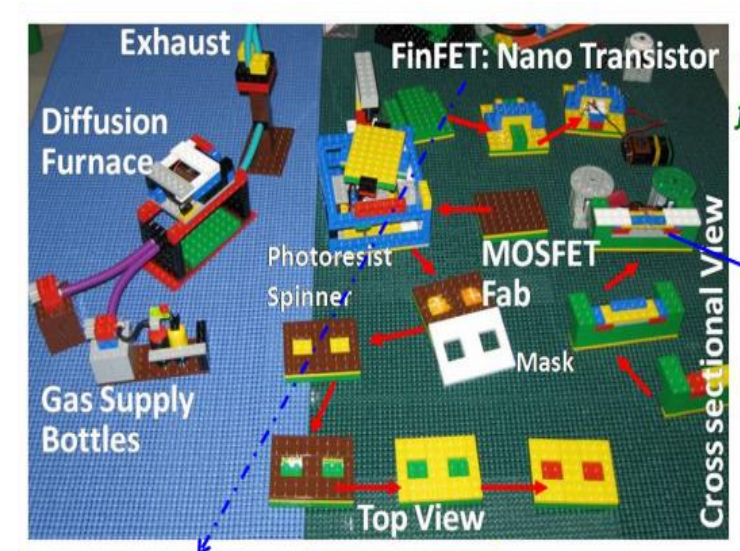

LEGOs: Used to Explain Processes for Fabrication of Micro \& Nano Switches
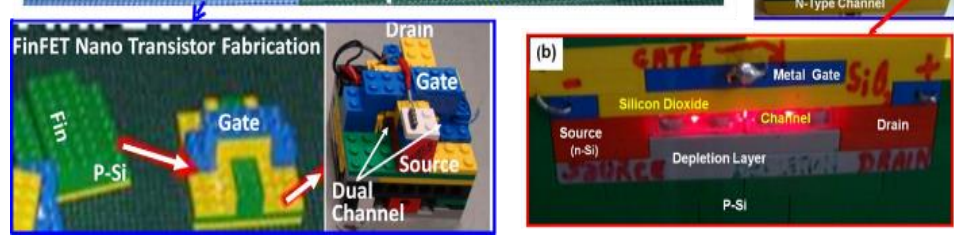

A unique feature of FBEIs presented in this paper is the use of LEGOs to explain complex concepts such as micro/nano fabrication, Metal Oxide Semiconductor (MOS) switching devices, and principle of operation of MOS Field Effect Transistor (MOSFET). Variations of MOSFET devices called NMOS, PMOS and CMOS as shown in Fig. 6 are explained using LEGO based FBEIs. LEGO constructions explain resist spinners, plasma oxidation processes, furnace

Fig. 7 DIANA

Modules;

DNA and

DIANA (a),

MOS based

digital logic

(b) and LEGO

based

breadboard (c).

\section{DNA Inspired Active Network Arrays (DIANA)}

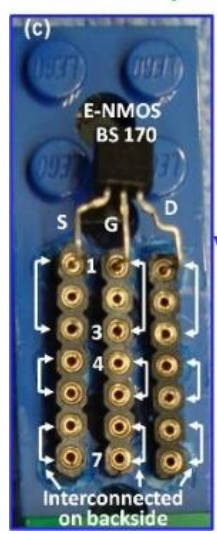

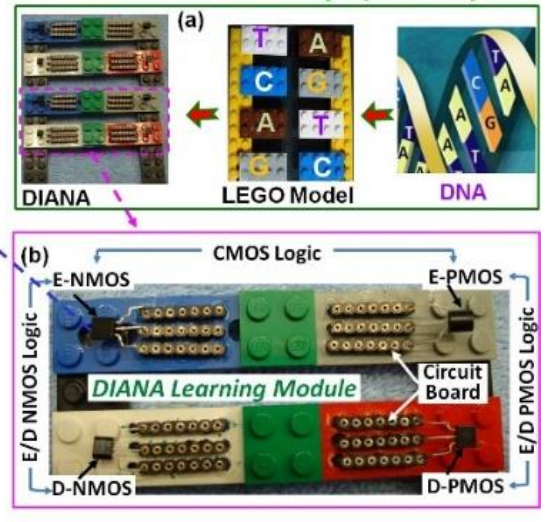

PreK - 8:

Beeper Controlled by

Positive Charge

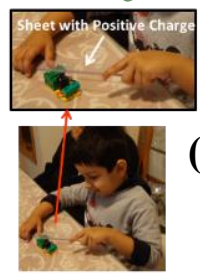

Static Charge Piano: Played by Static Charges

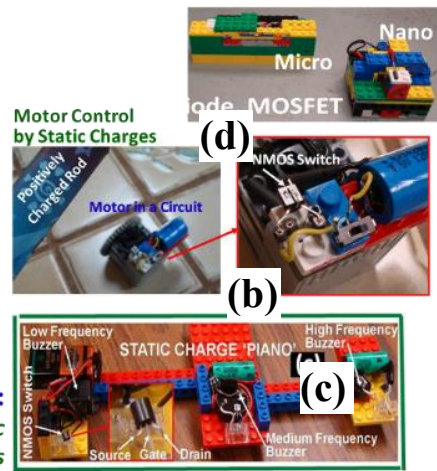

Fig. 8 Fun learning by computer switches.

exhaust, dispenser nozzles for the spinner, fabrication sequence for FinFET (a nano transistor switch) and MOS, plasma oxidation, etc.

A novel concept called DNA Inspired Network Arrays (DIANA), as shown in Fig. 7, excites all learners from HighSchool to Ph.D. DIANA explains (a) Microsystems to students with biomedical background and (b) DNA to students with engineering background as shown in Fig. 7. It also explains CMOS logic and other types of logic on one hand and help build creative hardware for learning on the other.

The computer switch-based modules shown in Fig 8 make learning fun for children in the K-5 range. LEGO-based static charge operable beepers (a), LEGO motor control (b), piano (c) and Micro and nano MOSFETS (d). The static charge piano uses three MOSFET based modules, each with a different frequency, that are switched on and off by positive or negative static charges. Learners love such LEGO-based learning activities unique in the world.

MOSFET based computer switches are unique for artificial intelligence systems; robotic nurses, patients and actresses.

Fig. 9 shows provocative learning using functional LEGO Microsystems; neural probe (a), pressure sensor (b) and comb drive used for acceleration sensors (c).

Wireless Control: Wireless control through static charges, light and Bluetooth, not easy to explain to K-8 children, explained by provocative LEGO modules. Computer switches, explained in the next activity, and photo sensors employed to build intriguing modules that excite the K-12 learners. As shown in Fig. 10, one module uses static charge and light to control a LEGO robot (a). A more complex system uses wireless link between three nodes (b). 
Vol. 9, Issue 6, June 2020

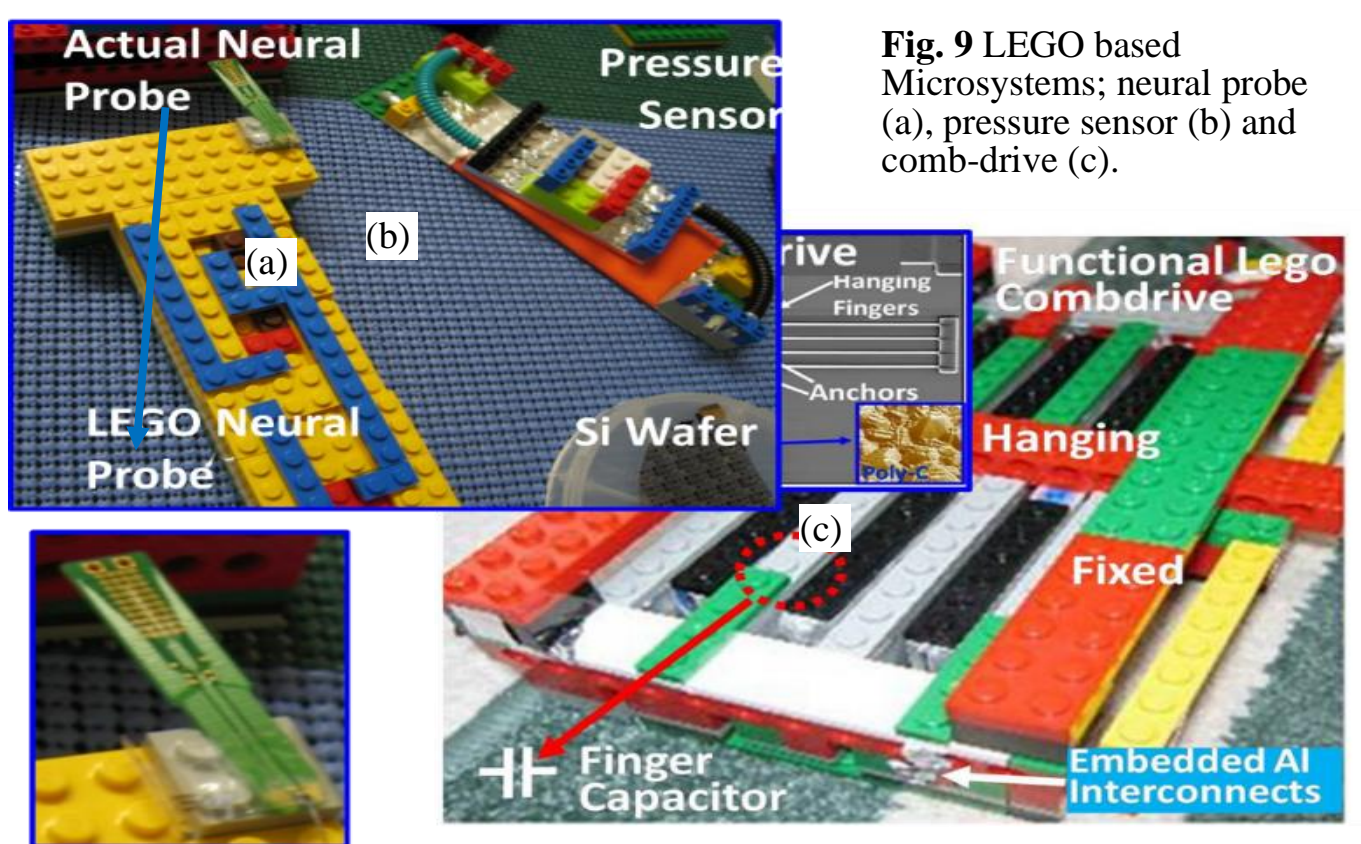

Miller Indexes: Another difficult concept to explain, even at the college level, is Miller indices (c) that are crucial for understanding Si micromachining processes frequently used in the fabrication of Microsystems or MEMS. Most important Miller indices are (100), (110) and (111) which refer to planes in a Si crystal. A direction perpendicular to plane (100) is [100]. Wooden cubes, paper pieces and a Rubik cube help explain directions and planes for Si crystals in a fun way as shown in Fig. 10(c).

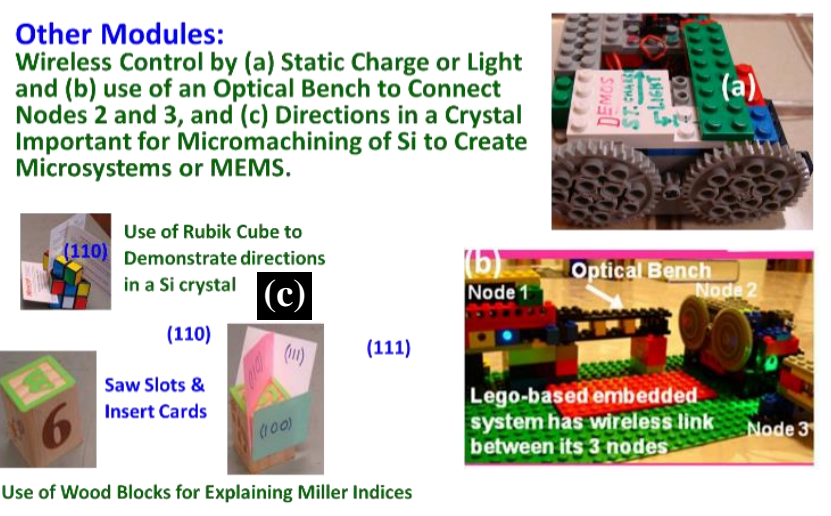

Fig. 10 Wireless control and Miller indexes.

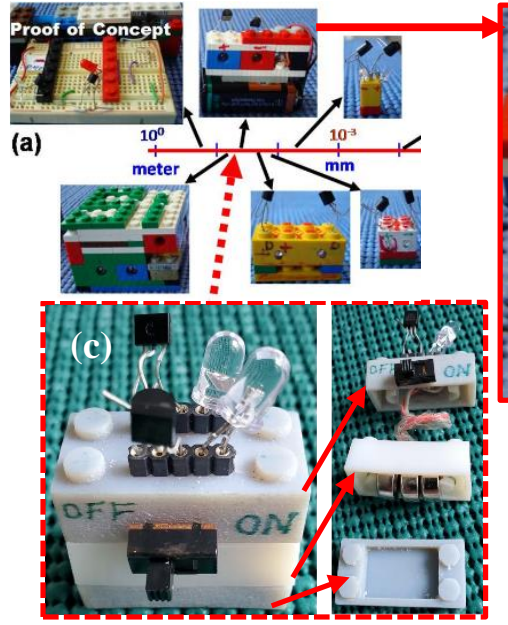

Fig. 11 Static charge sensors; miniaturization (a), sensor circuit diagram (b) and $3 \mathrm{D}$ printed sensor (c).

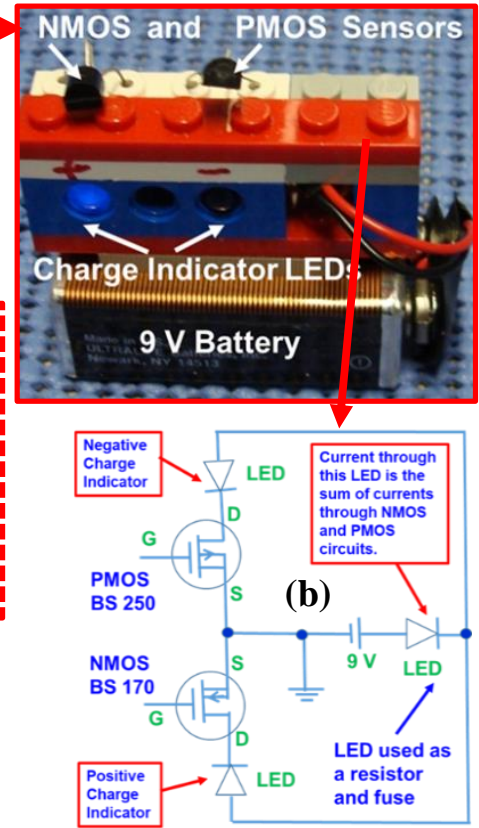

Miniaturization: The concept and understanding of miniaturization is important for micro and nano technologies. Miniaturization of LEGO FBEI static charge sensors, as shown in Fig. 11 (a), is fun way to explain sensors. All sensors shown in Fig. 11 can detect positive and negative static charges. NMOS detects positive charges while PMOS detects negative charges. The circuit shown in Fig. 11(b) is same for all sensors. The 3D printed sensor has integrated sensor, battery and circuits sections as seen in Fig. 11(c).

LEGO Gear Trains (LGT): LGT explain nano \& micro concepts, gear ratios, torque, energy of gears with different speeds, measurement of RPM (Revolutions Per Minute) and speeds of all the gears using an NXT-controlled servo motor with one degree of precision as shown in Fig. 12. RCX motor drives the gear train and the gear ratio is 5 slowing down the gears $1-11$ with the last gear moving $5 \mathrm{~nm} / \mathrm{s}$ as shown in Fig. 12 (a). Thus, the total slow down factor is $5^{11}$. Fig. 12 (b) shows an NXT motor used to measure the speed of gear attached to servomotor and other gears. 

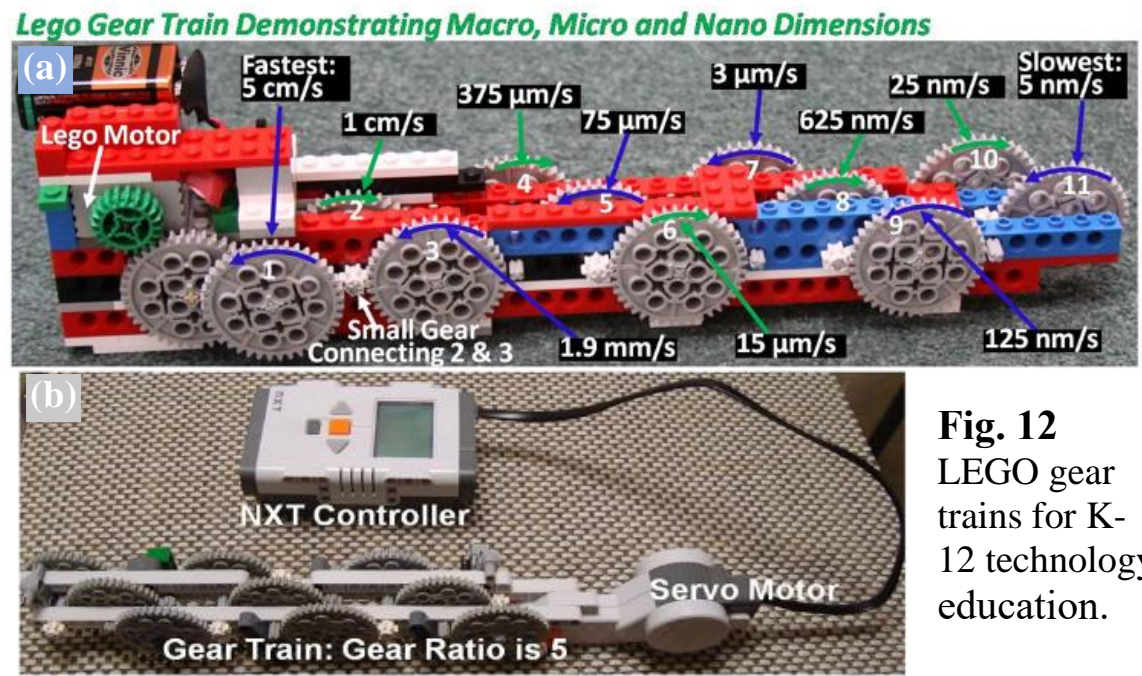

Fig. 12

LEGO gear

trains for $\mathrm{K}$ -

12 technology

education.
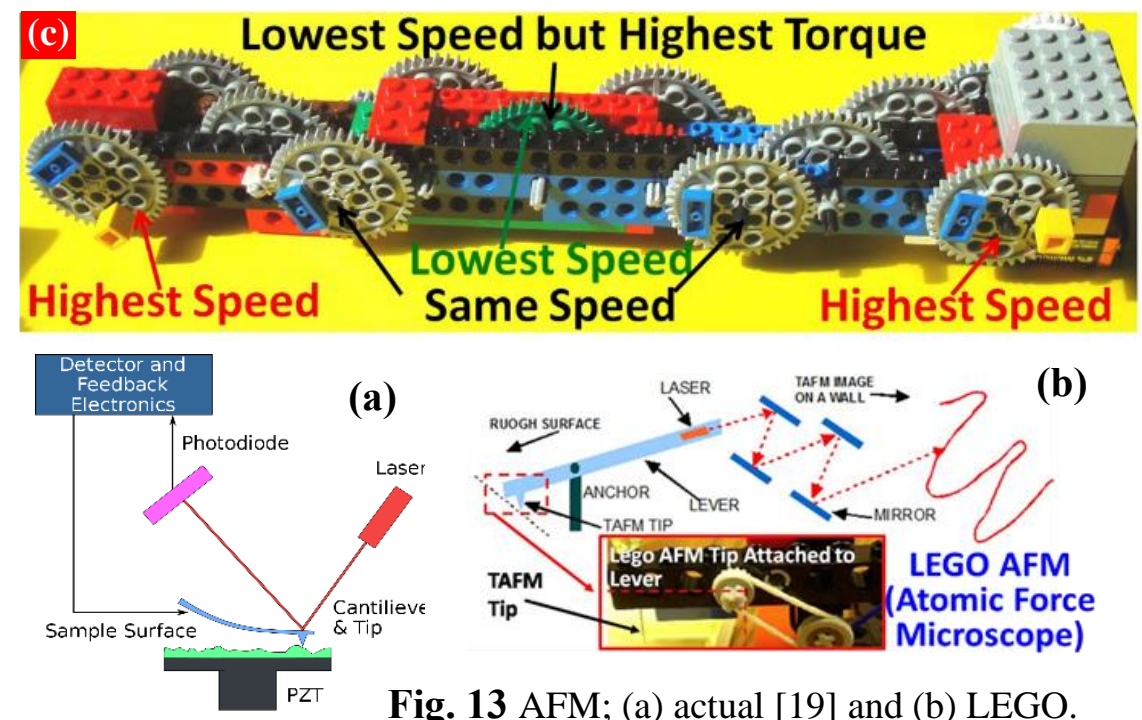

Fig. 13 AFM; (a) actual [19] and (b) LEGO.

The most intriguing part of the gear train project is a question asked by a second grader from a local elementary school when the author was presenting the gear train shown in Fig. 12(a). The second grader says, "I do not think that gears $5-11$ are moving in Fig. 12(a). I can't see them moving."

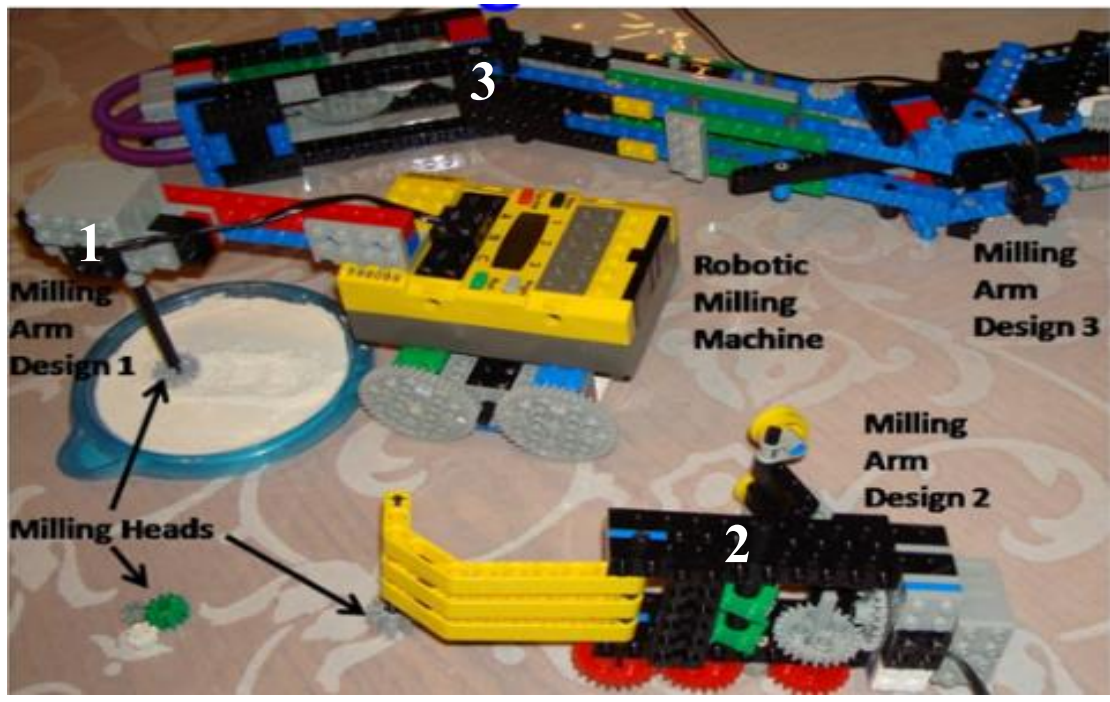

Fig. 14 LEGO milling machine designers. 


\section{International Journal of Advanced Research in Computer and Communication Engineering}

Vol. 9, Issue 6, June 2020

The author took two weeks to figure out and convince the second grader by building another gear train shown in Fig. 12 (c) that uses 11 gears with the green gear having the lowest speed. To the left of green gear, by reversing the gear ratio, the speed of gears increases such that gears 1 and 11 move with the same speed while the green gear appears

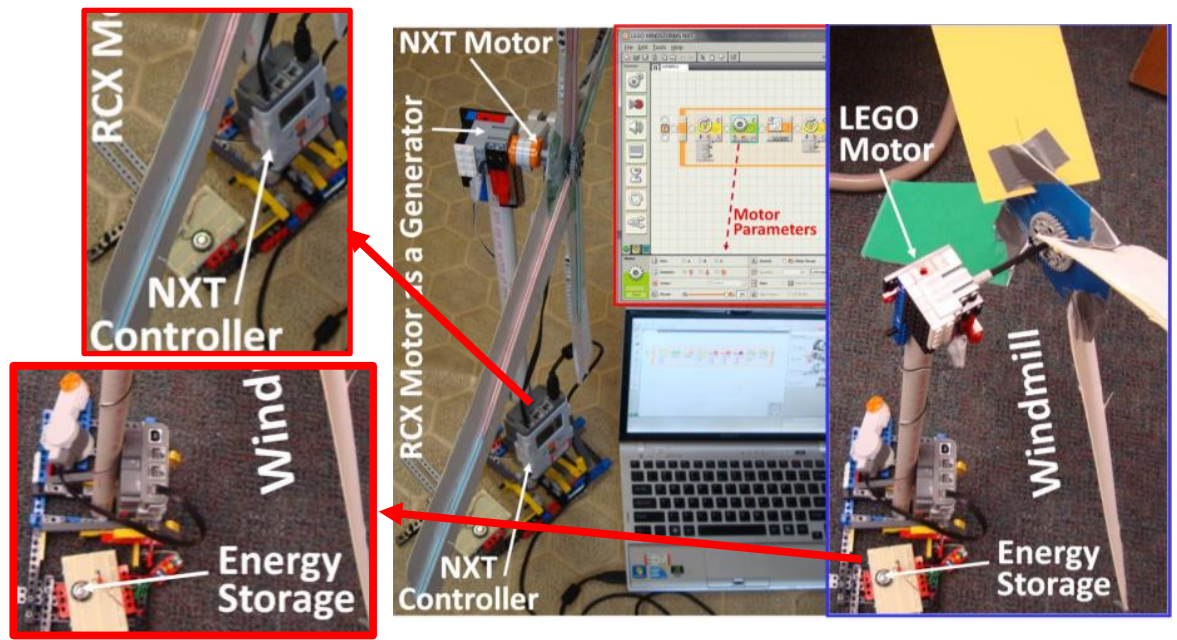

Fig. 15 Windmill Using LEGO Parts.

stationary. The second grader was convinced and said "the green gear must moving making gear 11 to move fast".

Atomic Force Microscope (AFM): An AFM can see atoms [19] and Fig. 13 demonstrates the principle of AFM in a very simple way using LEGOs. A tip, attached to shorter end of a lever, moves over a rough surface with the help of a LEGO motor construction. Light of a LASER attached to longer end of beam, after multiple reflections, hits a screen that shows a magnified view of the rough surface under study.

LEGO Robotic Milling Machine: Fig. 14 shows three different LEGO designs of a milling machine that uses sand to demonstrate the milling principle employing LEGO gears as milling heads. It is programmable using RCX controller. Milling arm 3 has a complex design with multiple degrees of freedom.

Design, Building and Testing of Multiple Windmill Designs: As shown in Fig. 15, LEGO RCX motors used as generators for windmill designs employ 1 or $5 \mathrm{~F}$ capacitors for energy storage. The NXT controllers used to make the windmill parameters programmable leading to tremendous learning and entrepreneurial activities. A simple box fan, placed in front of windmill, drives the windmill.

K-12 Chip and Intriguing Nano, Micro and Macro K-12 Modules: As shown in Fig. 16, (a) soap bubble skin thins due to evaporation causing changing colors, (b) bubble levitation due to similar static charges on bubble and Van De Graff (VDG) globe, and (d) K-12 LEGO chip with sensors. Teachers from a local high school suggested that if large size NMOS or PMOS computer switches can be designed that are visible with a naked eye they can explain CMOS and related switches as shown in Fig. 16.

Fig. 16 (e) shows a LEGO model of a carbon nanotube. It is interesting to note that (f) a rough measure of humidity level in a bathroom is how soon the soap bubbles burst.

Energy Modules and Energy Scavenging From Static Charges: Typically p-n junction is used for converting ac to dc voltages employing the voltage rectifier concept. Fig. 17 shows unusual experiments; LEDs as a solar cell and energy scavenging from static charges. A $1 \mathrm{nF}$ ceramic capacitor was used to store scavenged energy as it has a low leakage current.

Intriguing Math and Trigonometry Modules: Fig. 18 shows some fascinating modules, liked by grades 4 - 12, as this is a provocative approach to learn mathematical and geometrical concepts. For example, as seen in Fig. 18(a), the LEGO beam $\mathrm{c}$ is hinged at point $\mathrm{h}$ (the origin) and its other end is attached to a free-hanging beam $\mathrm{b}$. As the beam $\mathrm{c}$ rotates by an NXT motor, programmable by NXT controller, the beam b stays vertical making a right angle with beam a. For different values of angle $\mathrm{e}$, Sin, Cos and Tan can be defined. Cos 45 is $\frac{1}{\sqrt{2}}$ but $\operatorname{Cos} 135$ is $-\frac{1}{\sqrt{2}}$ due to $-\mathrm{a}$. This helps to define all trigonometric function without memorization! 
Vol. 9, Issue 6, June 2020

Fig. 16 Nano, Micro and Macro K-12 Modules; (a) soap bubble skin thins causing changing colors, (b) bubble levitation due to similar static charges bubble and VDG globe, and (d) K-12 LEGO chip with sensors.
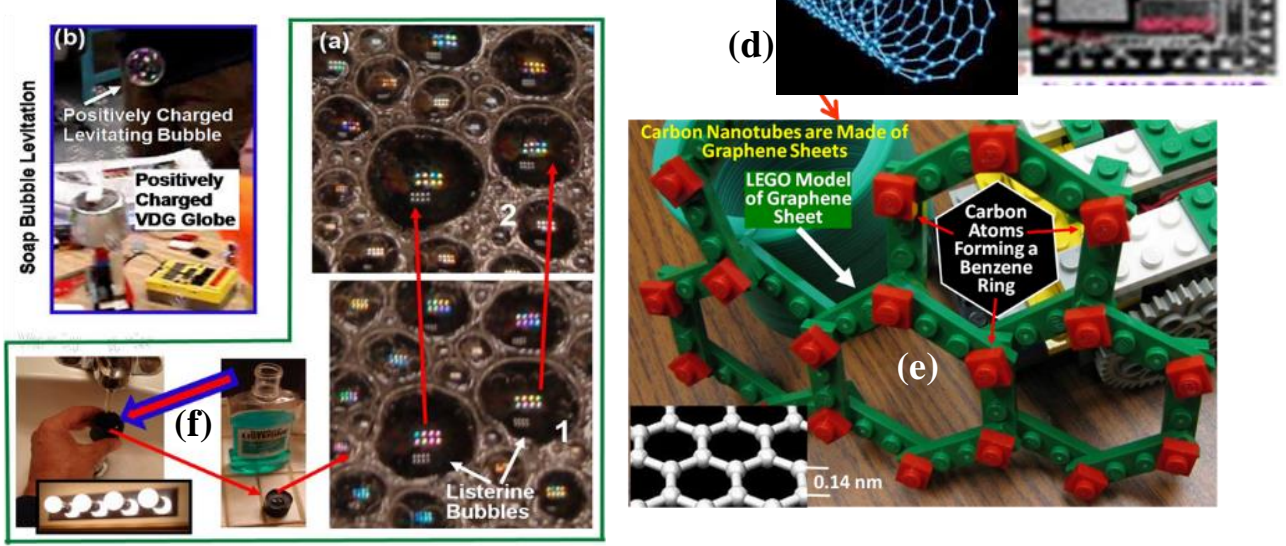

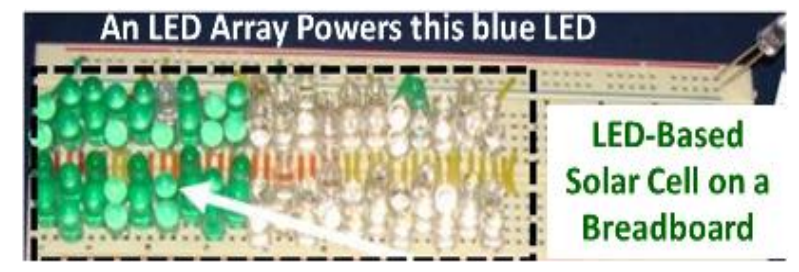

(a)
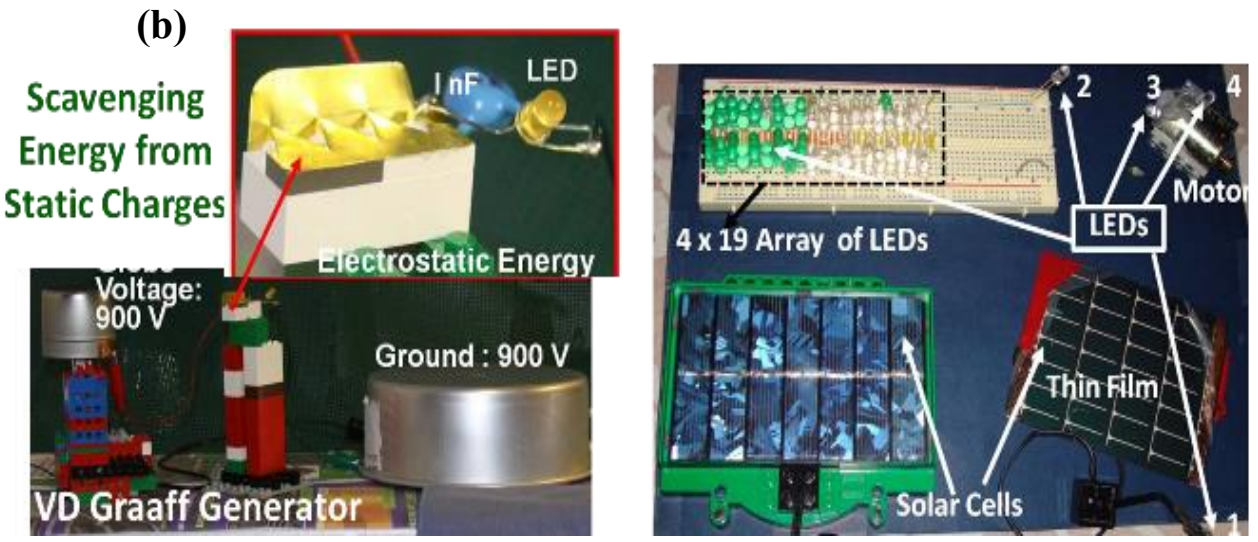

Fig. 17 LEDs as a solar cell (a) and energy scavenging from static charge (b).

Fig. 18 (b) provides a more detailed view. Now by attaching an NXT motor, controlled by an NXT controller, different angles are programmable. While Fig. 18 (c) teaches how to calculate area of a circle by programming an RCX controller, Fig. 18(d) teaches number series such as 1, 2, 3, ?, 5, . A first grader when asked to fill-in the question mark, he first looked at LEGO constructions 1, 2.3 and 5 before he made the missing LEGO construction.

Fig. 18(d) shows how a programmable LEGO robot follows a circular black line and measures the area of a circle. Such a concept is extendable to other planer shapes.

Sensors and Systems: Fig. 19 (a-d) shows examples of sensors and systems. A LEGO based van de Graaff (VDG) is designed, built and tested as an example of a re-configurable system as shown in Fig. 19(b). Leather or nylon is used for the upper pulley and Teflon is used for the lower pulley that gives more static charge, positive on the top and negative on the bottom pulleys, as shown in Fig. 19(c). As the motor in VDG is programmable, as shown in Fig. 19(d), either by 
Vol. 9, Issue 6, June 2020

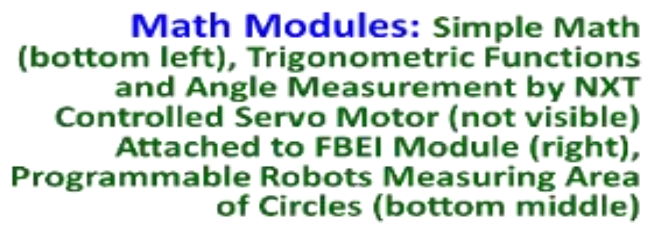

Prek - 3 Math
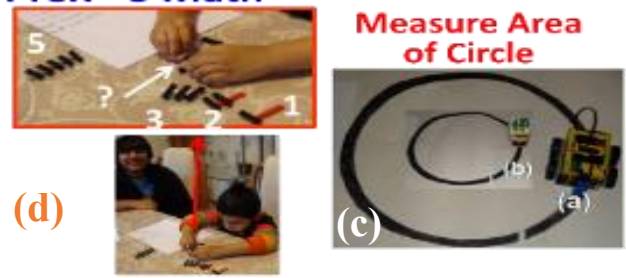

Fig. 18 Intriguing K-12 math modules.

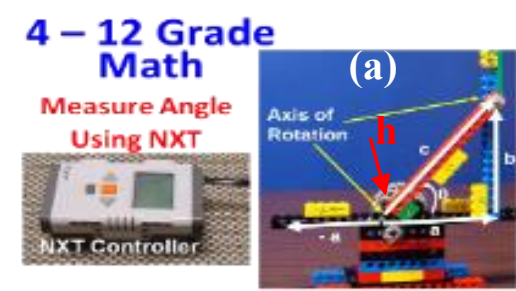

Compute Trigonometric Functions

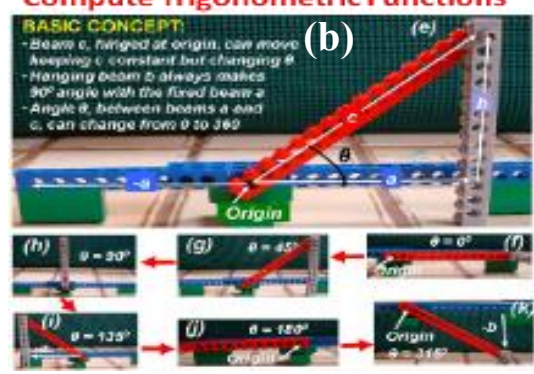

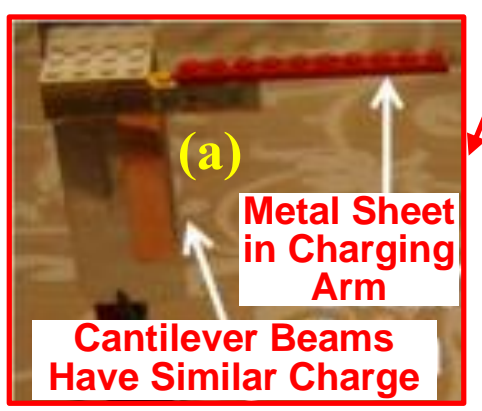

Fig. 19 System integration; VDG, cantilever beam and static charge sensors and NXT

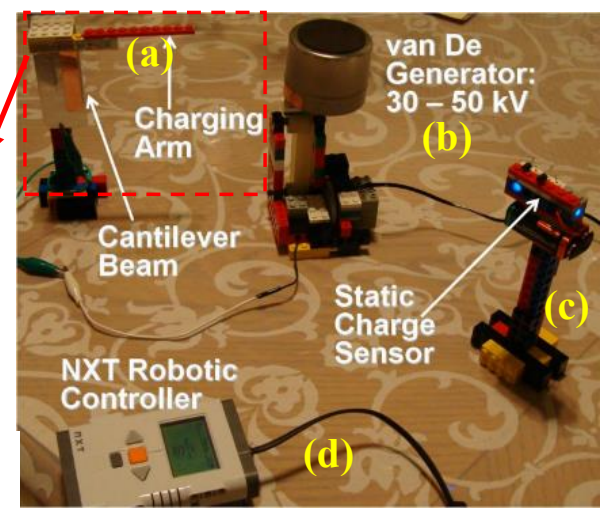
Controller.

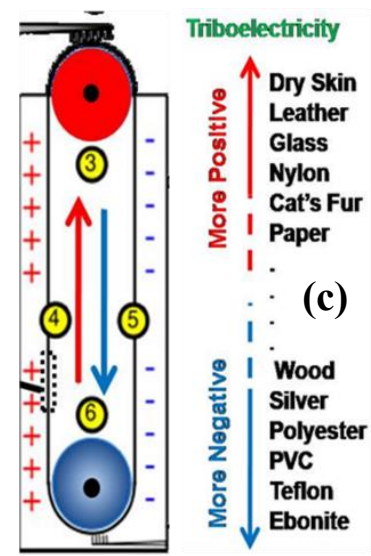

RCX or by NXT (shown in Fig. 19d) controllers, the globe static charge voltage is programmable. Using static charges, a cantilever beam can be actuated, as shown in Fig. 19 (a), to demonstrate the principle of an airbag sensor.

Fig. 20 further explains this subject by using static charges. Fig. 20 shows static charge sensors (a), demonstrates a balloon levitation (b) and a programmable LEGO VDG (c).

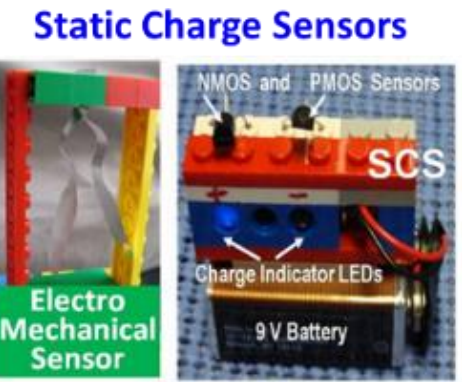

(a)

Fig. 20 Computer switches; (a) electro-mechanical and static charge sensors, (b) ES levitation and (c) programmable LEGO VDG.
Capacitive Sensor: Principle of Operation
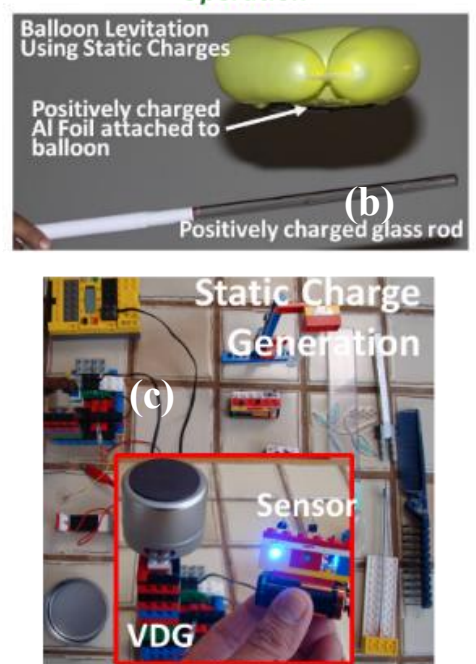


\title{
International Journal of Advanced Research in Computer and Communication Engineering
}

\author{
Vol. 9, Issue 6, June 2020
}

Microcontroller Powered by a LEGO Motor: Fig. 21 shows powering of a microcontroller using LEGO motor that is world's first. Why power a micro controller with a LEGO motor? When exciting K-12 children, one has to introduce one new item at a time. As children already know about LEGO motor, LEDs and a breadboard, one can introduce a programmed microcontroller. A microcontroller is the brain of a system or microsystem. For example, a typical American home has dozens of microcontrollers. They are found in toys, refrigerators, sprinkler systems, etc.

Here is the challenge in this project; a LEGO motor can deliver up to $9 \mathrm{~V}$ DC power and will provide only positive or negative voltages depending upon the direction of rotation of motor axis. This is a big challenge without introducing voltage regulators and complex rectifier circuits. The full wave rectifier shown in Fig. 21 (a) is made using LEDs instead of regular diodes. An interesting aspect of LED rectifier circuit is its ability to show which way the current flows as seen in Fig. (b). The output of a LEGO motor can be over $5 \mathrm{~V}$ depending on the motor speed. A blue LED connected across the rectifier output (forward biased) keeps the voltage in the range of $2.8-3.2 \mathrm{~V}$ (acting as an approximate voltage regulator). This voltage range is typical of forward biased blue LED as seen in Fig. 21 (c). Thus, the microcontroller programmed to blink a green LED has a supply voltage of $2.8-3.2 \mathrm{~V}$.

System Integration-I: Fig. 22 shows interesting examples of inexpensive programmable LEGO robots including a \$ 17 robot that follows a line. One can build LEGO-like motor using a 50 cent motor as shown in Fig. 22(a). This can help build a low cost robot. By using NMOS or PMOS computer switches this robot can respond to static charges.

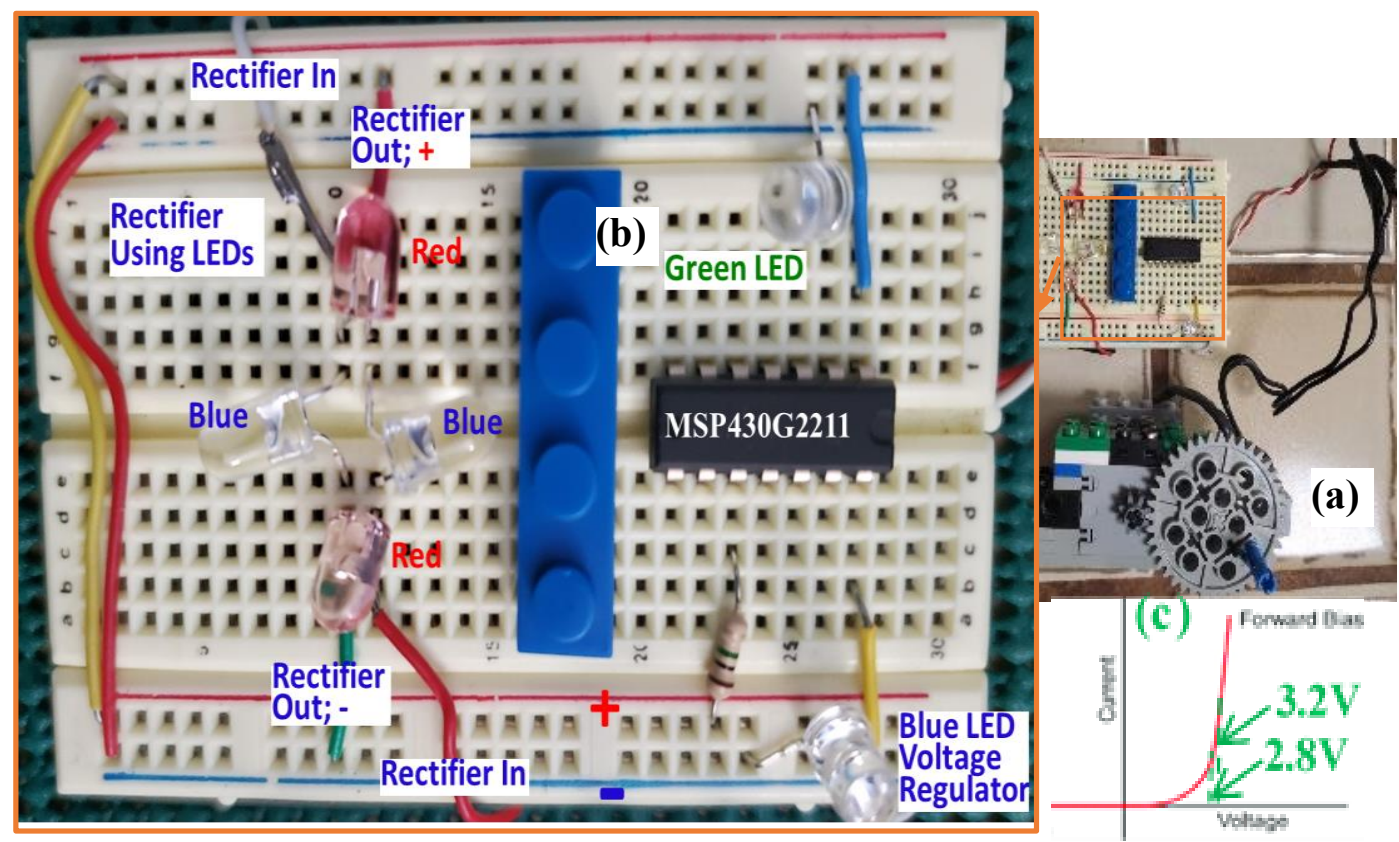

Fig. 21 Microcontroller powered by LEGO motor.

Fig. 22 (b) shows a line tracker robot that uses a microcontroller programmed in C code. It uses two LEGO motors. TI's LauchPad system, available for $\$ 10$ is an excellent system to learn programming in $\mathrm{C}$ code.

System Integration-II: Fig. 23 shows another example of different types of system integrations. Fig. 23 (a) shows a LEGO packaging of a polycrystalline diamond neural probe developed by researchers at Michigan State University [16]. Fig. 23(b) shows an RCX LEGO robot controlled by static charges. This is done using NMOS computer switch which responds to positive charges. Using two commercial block systems, LEGO and Fisher, a cluster van de Graff generator designed and built provides more current as seen in Fig. 23 (d). The operation of VDG shown in Fig. 23 (c) explains tribo-electricity and design of VDGs.

\section{Nature-Made Systems (NS) and Man-Made Microsystems (MS):}

New Learning Concept: NS and MS have similarities and differences:

NS and MS both have four digital fundamentals: A, T, G and C bases for NS and four MOS logic types for MS as pointed out in Fig. 7. NS uses proteins, neuro-transmitters and Enzymes but MS uses electrons and holes for operational control. In NS, genes consist of base pairs but, in MS, logic gates consist of Metal Oxide Semiconductor (MOS) devices. 
International Journal of Advanced Research in Computer and Communication Engineering

Vol. 9, Issue 6, June 2020

(a)
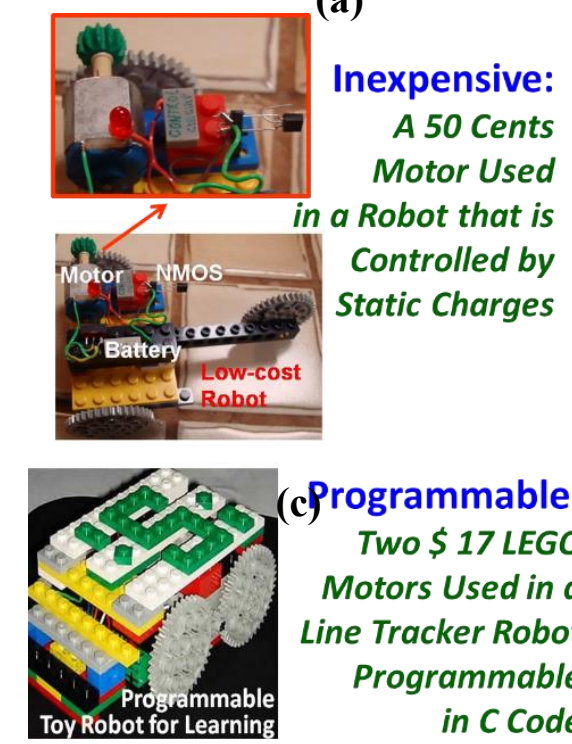

(c) Programmable: Two \$ 17 LEGO Motors Used in a Line Tracker Robot Programmable in C Code

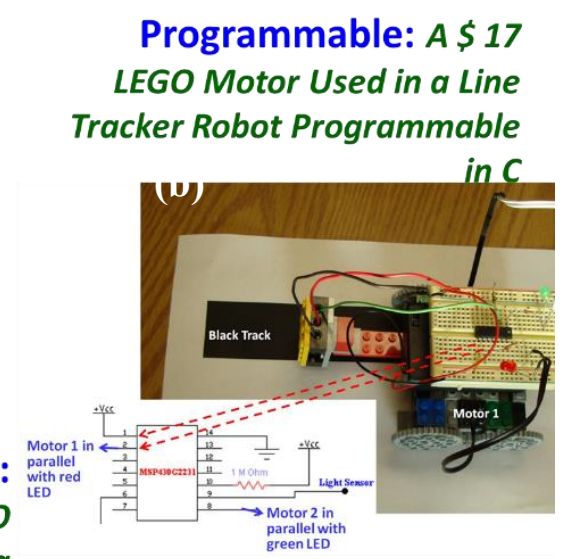

Fig. 22 System integration using programmable LEGO robots.

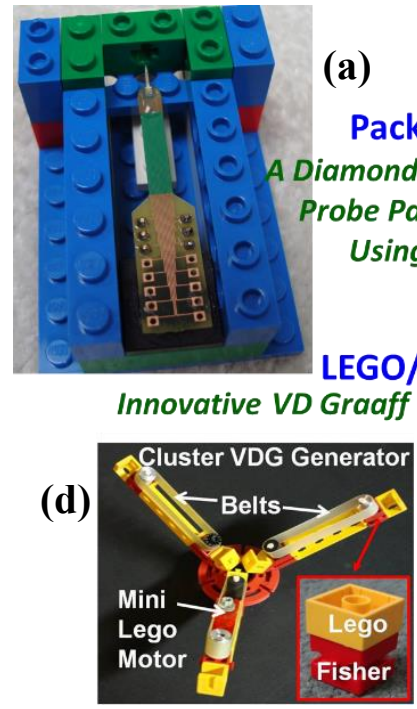

(b)

(a)

Static Charge Control:

Packaging: RCX Robot Equipped with a Computer Switch Control

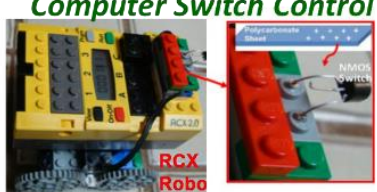

EGO/Fisher VDG Charge Generators: Innovative VD Graaff Generators Built Using Plastic Blocks

(d)

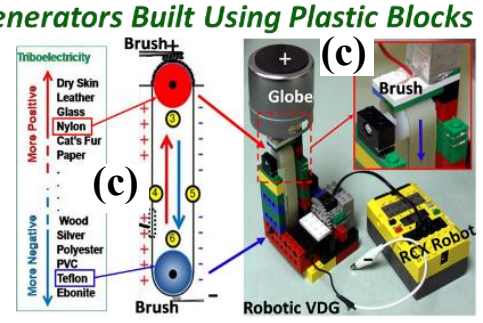

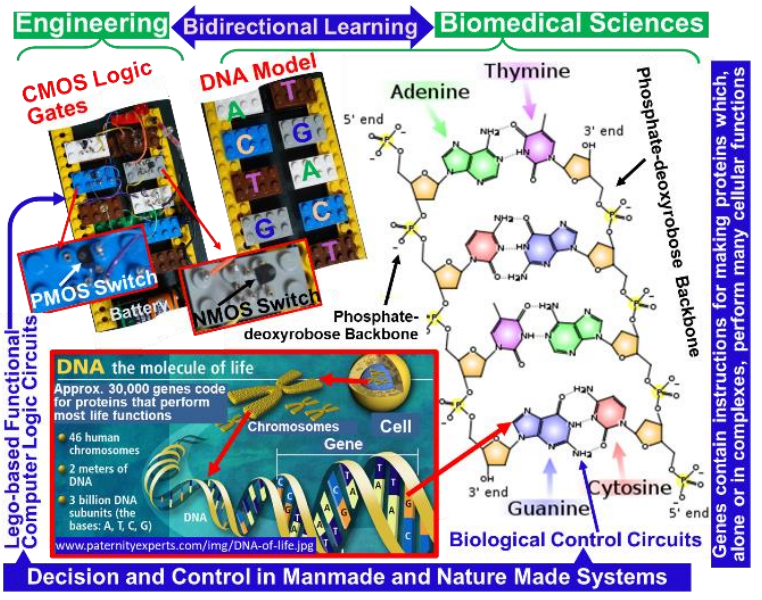

Fig. 24 Nature made systems (NS) and Micro-Systems (MS).

Fig. 23 System integration examples.

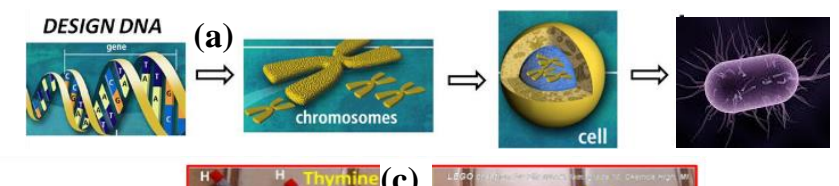

(b) Cell

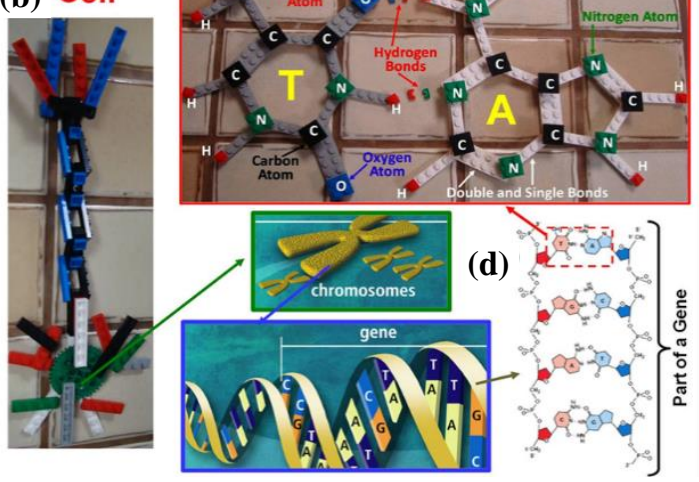

Fig. 25 Creation of bacterial life and explanation of related concepts; (a) DNA design, (b) 
Vol. 9, Issue 6, June 2020

Fig. 26 E. Coli detects lactose.
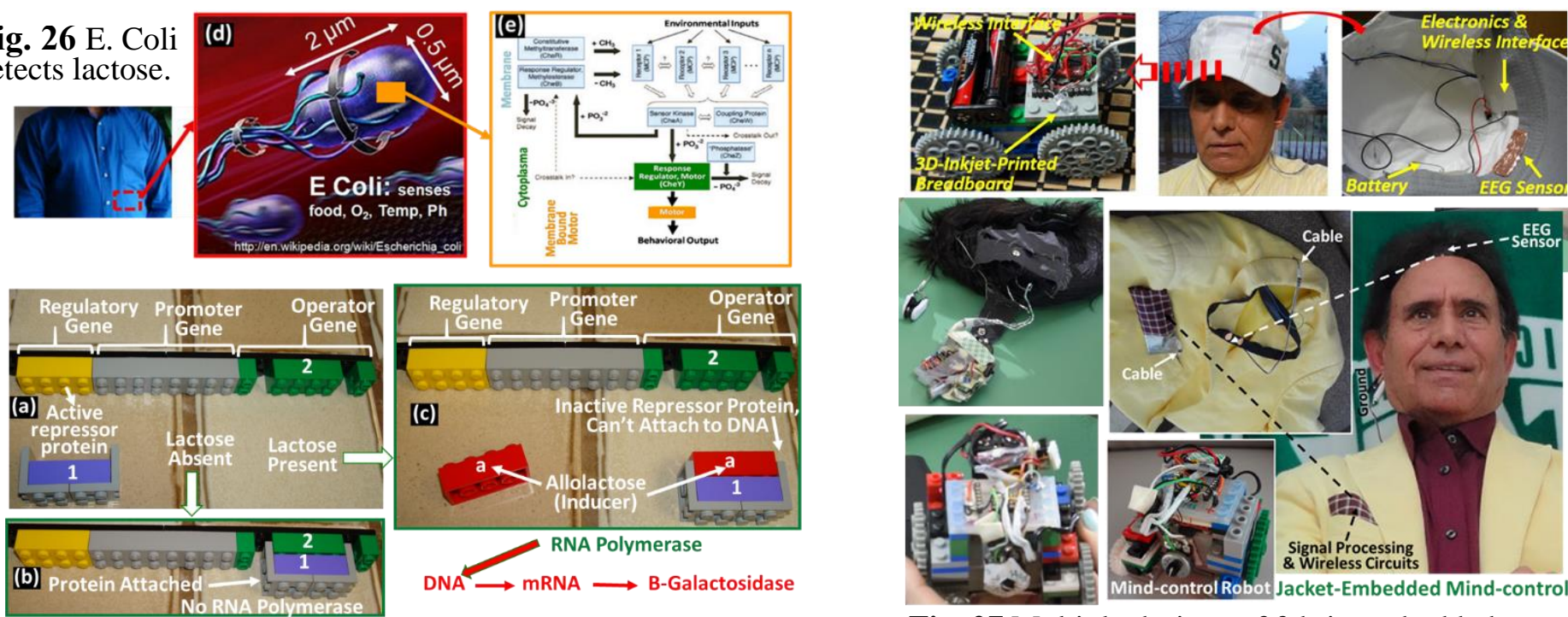

Fig. 27 Multiple designs of fabric-embedded mind-control robots.

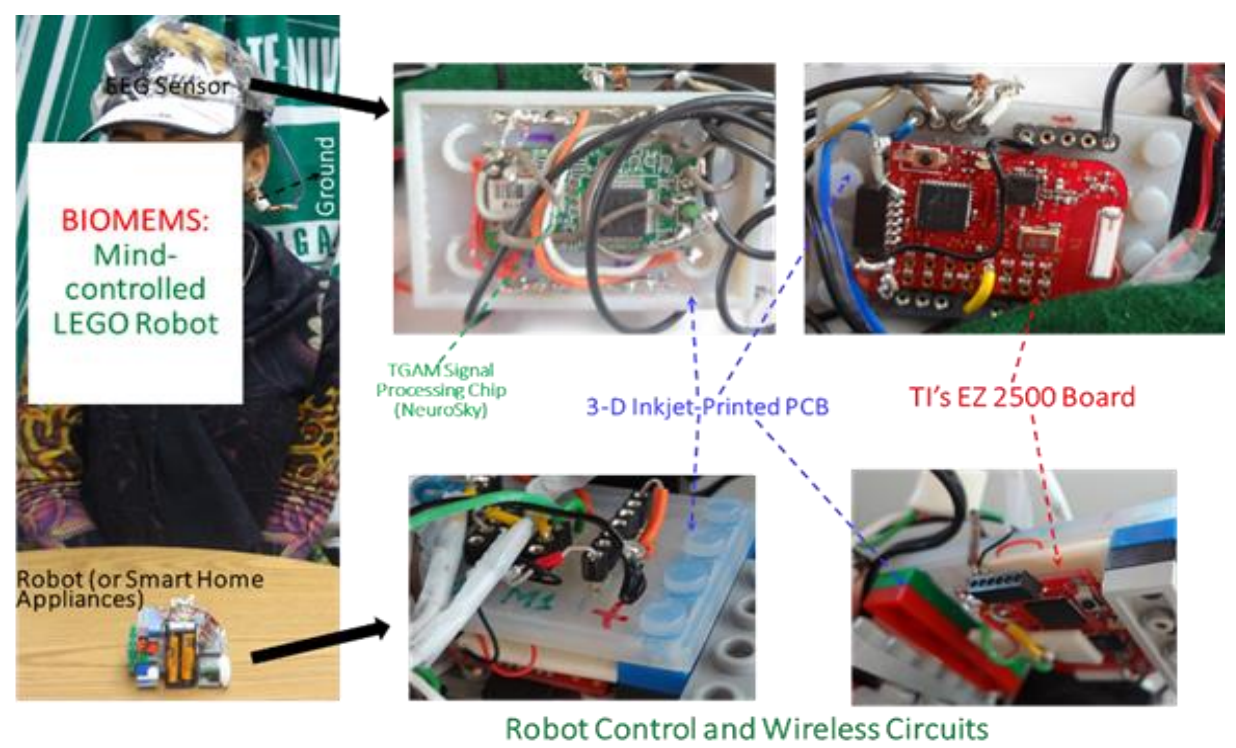

Fig. 28 Details of cap-mounted mind-control of a LEGO; robot and EEG ends.

Bidirectional learning is possible by this example as shown in Fig. 24. Starting with engineering, as pointed out in Fig. 7, there are four basic component used to built today's computer logic (or Microsystems). Thus, the engineers can use analogy to learn about four bases, A, T, G and C, the basis of 23,000 human genes in the DNA.

On the other hand, biosciences learners can learn about computer logic by analogy. This interesting analogy can help learning and research in biomedical engineering.

\section{Creation of Bacterial Life:}

With new bacterial species created by scientists in the lab [20][21], learning has become very exciting on one hand but very challenging on the other. This paper uses LEGOs to make learning fun as shown in Fig. 25 by using LEGOs to create structures mimicking cells (b), genes (c) and DNA (c).

How Does E. Coli Detect Presence of Lactose?

While most types of E. coli are harmless and even keep our digestive tract healthy, some strains can cause diarrhea if contaminated food or fouled water are consumed.The E. Coli bacteria is a living nanosystem as seen in Fig. 26 (d-e).

E. coli can sense presence of lactose using three genes; regulatory gene, promotor gene and operator gene. Using a LEGO model, this paper explains the sensing process using these three genes in the E. Coli DNA. As shown in Fig. 26 (a), the regulatory gene releases active repressor protein (ARP) that keeps moving around. If there is no lactose, the ARP attaches to operator gene due to electrostatic forces. 


\section{International Journal of Advanced Research in Computer and Communication Engineering}

Vol. 9, Issue 6, June 2020

In the LEGO construction the blocks 1 and 2 have magnets inside to facilitate the attachment. The above process keeps repeating until there is lactose present. When the lactose is present the allolactase attaches to ARP as shown in Fig. 26 (c) coverting ARP to inactive repressor protein which can't attach to operator gene. When this happens the E. Coli, using some of the processes shown in Fig. 26 (d), knows that there is lactose present.

Mindcontrolled LEGO Robot: An interesting application of fabric-embedded Microsystem controlling a LEGO robot, as shown in Fig. 27, has excited learners worldwide [22][23][24][25]. This has been reported 84 times worldwide.
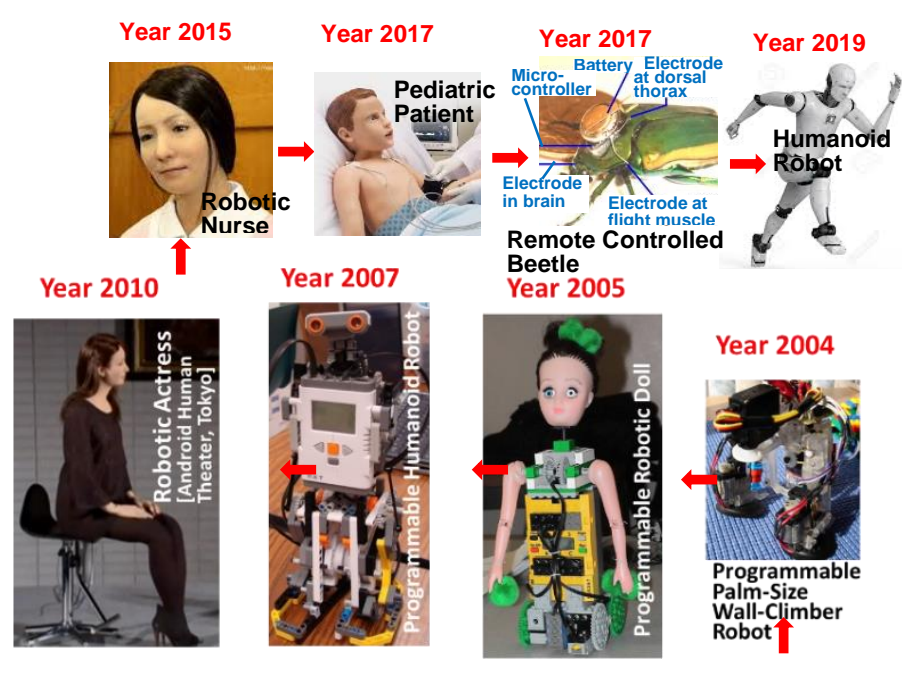

Fig. 30

Technology

Assisted Cancer

Education and

Prevention.
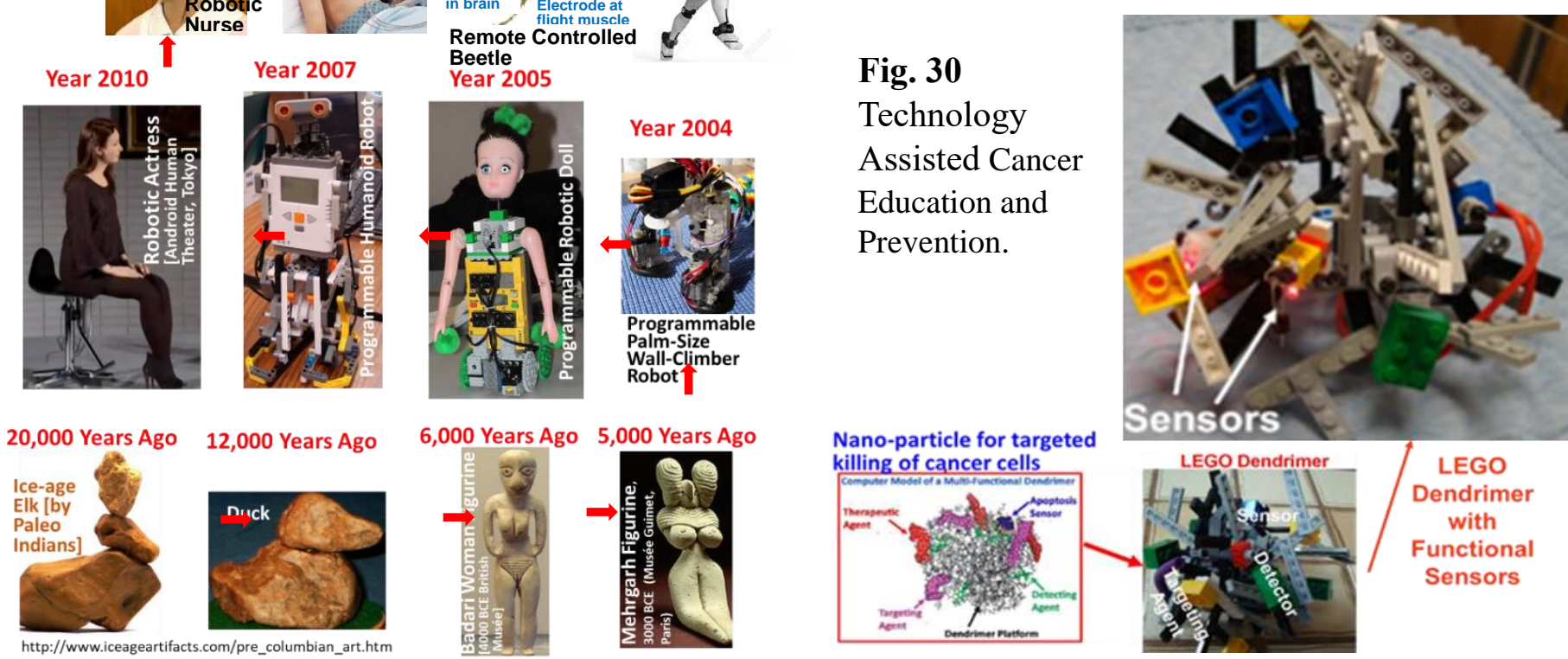

Fig. 29 History of technology.

Multiple designs have been prepared and tested as shown in Fig. 27; the popular being the cap-mounted mind control as shown in Fig. 29B. The main part of design is determing mind's attention level on a scale of $0-100$ by finding an algorithm of EEG data using alpha and beta brainwaves. This requires separating these two waves from the raw EEG signal using Neurosky's TGAM chip. As shown in Fig. 28, the attention level signal from the TGAM board (the EEG end mounted in cap) is interfaced with one of the EZ2500 transeiver boards that wirelessly communicates with another EZ2500 board mounted in the LEGO robot using 2.4 GHz signal. 3D printed circuit boards (PCB) lead system integration at robot and EEG ends.

Currently, an empathy-controlled LEGO robot is being developed. This robot is expected to help identify and treat empathy related problem s; narcisacissm, sociopathy and psycopathy, etc.

\section{Use of New Technologies}

Development of new technologies dates back to stone age as shown in Fig. 29. More recently, artificial intelligence had led to amazing robots [26][27]. An interesing example, a blend of artificial and real intelligences, is a remote controlled beetle [28][29]. This paper reports new technology assisted learning and research modules.

\section{Technology Assisted Cancer 7Education/Prevention (TACEP):}

To develop trans-disciplinary learning areas that are unusual and game-changing, this paper, as shown in Fig. 30, introduces Technology Assisted Cancer Education/Prevention (TACEP) using LEGO creations. Chemicals can accumulate in the developing breast tissue during ages of $10-15$ years [30][31]. Studies show that in majority of cases these chemicals cause breast cancer 25 - 30 years later [31]. TACEP creates awareness about the dangers of exposure to toxic chemicals at an early age including childhood.

A LEGO model mimicking the actual dendrimer has functionalities of cancer killing nanoparticle as shown in Fig. 30. Nanoparticles for targeted killing of cancer cells are used in cancer research [32][33]. This paper describes a LEGO 


\section{International Journal of Advanced Research in Computer and Communication Engineering}

Vol. 9, Issue 6, June 2020

dendrimer with functional sensors that mimic killing of cancer cells. These sensors with MOS devices are activated by static charges which mimic presemce of cancer.
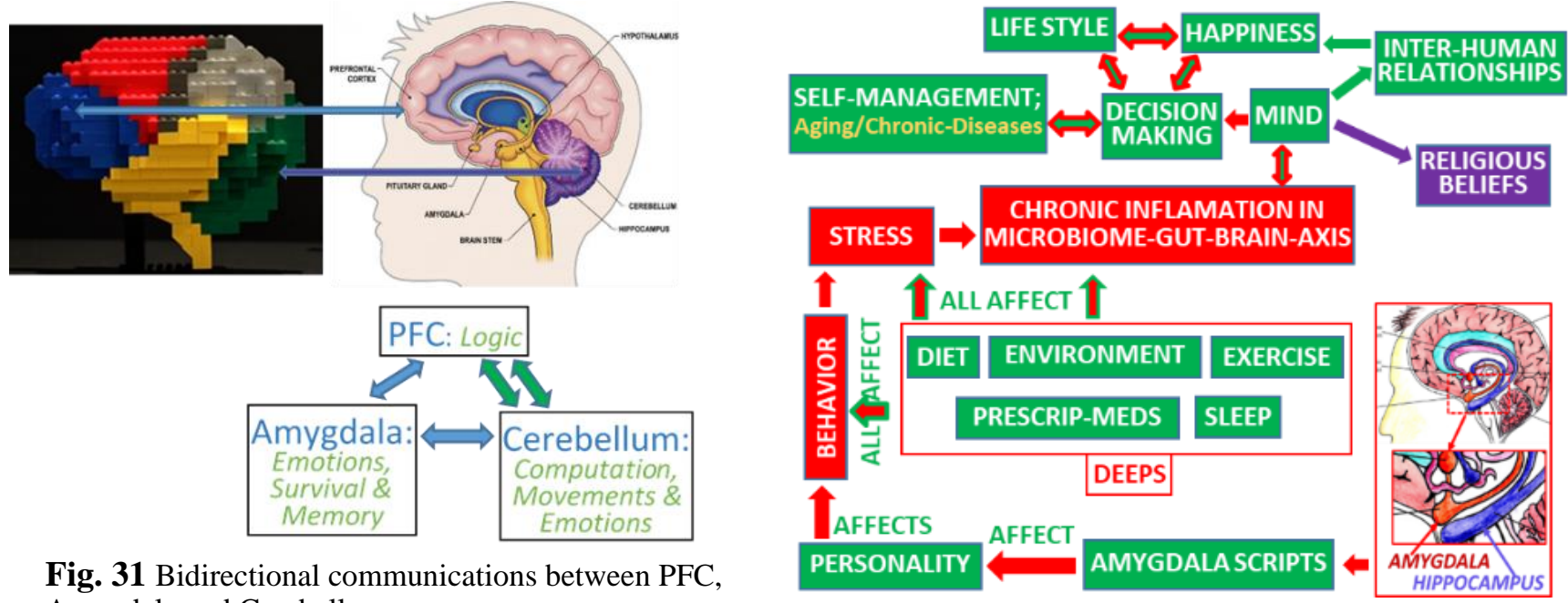

Fig. 31 Bidirectional communications between PFC, Amygdala and Cerebellum.

Fig. 32 Suggested model of interrelated factors affecting mind.

Another aspect of this research is ways to prevent initiation of cancer using mind. A new scientific model of mind shows that mind is leader and decision maker of anything and every thing that humans do [34][35]. As shown in Fig. 31, three parts of the brain playing a major and crucial role in human decision making are Pre-Frontal Cortex (PFC), Amygdala and Cerebellum. The amygdala is responsible for the perception of emotions such as anger, fear, and sadness, as well as aggression control. In the new model of of mind, PFC, Amygdala and Cerebellum play the most important role [34][35]. According to this model, mind is an algorithms based on data generated mainly by these three parts that, of course, communicate with other brain parts including Microbiome-Gut section.

As shown in Fig. 32, five factors, called DEEPS, affect behavior, stress and inflamation that affects mind or decision making. As inflamation is major cause of cancer, one can pay attention to DEEPS to avoid cancer. Other factors mentioned in upper part of Fig. 32 are also controlled by mind. Thus, mind can help avoid cancer. Boosting immune can

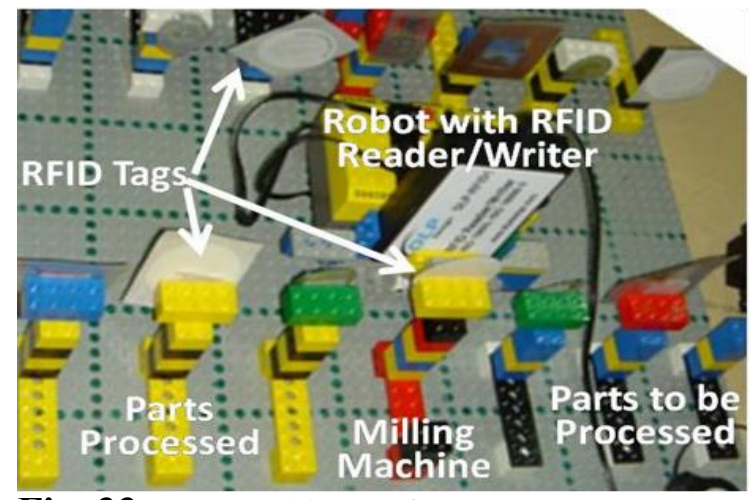

Fig. 33 TABI; table-top factory.

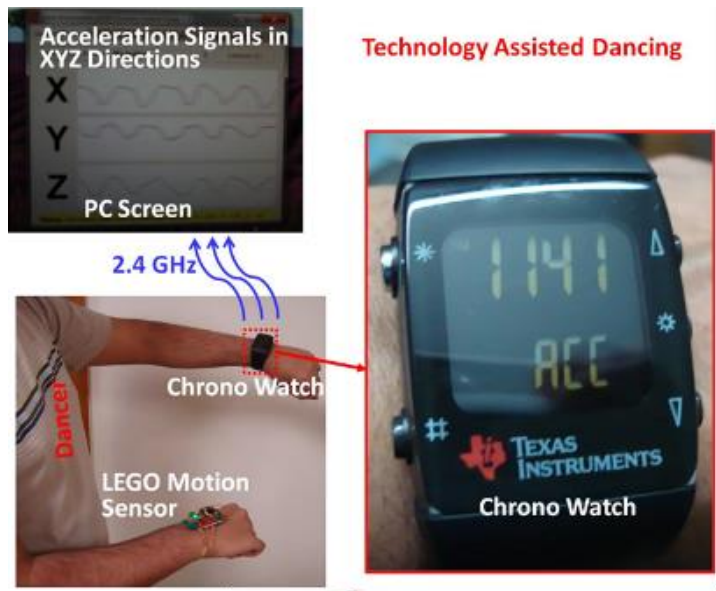

Fig. 34 Technology Assisted Dancing.

also help avoid cancer [36] and the decision to boost immune system comes from mind as mind is the leader.

\section{Technology Assisted Business Innovations (TABI):}

As shown in Fig. 33, the TABI helps to explain how radio frequency identification (RFID) can be tested on a table using a LEGO robot equipped with RFID reader. For every station, processed and unprocessed parts have RFID tags. The robot can take inventory and report the results to the factory manager.This approach of study can be applied to other areas such as warehouses, stores, etc. 
Technology Assisted Dancing (TAD):

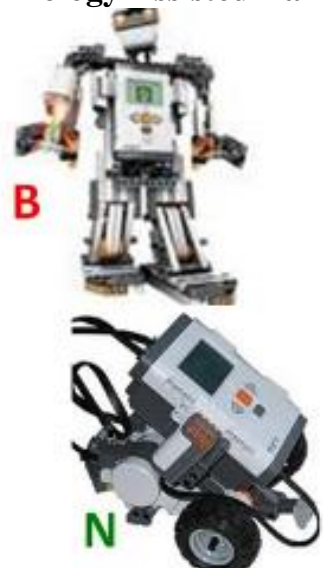

Fig. 36 Technology Assisted Smart Solarsystems.
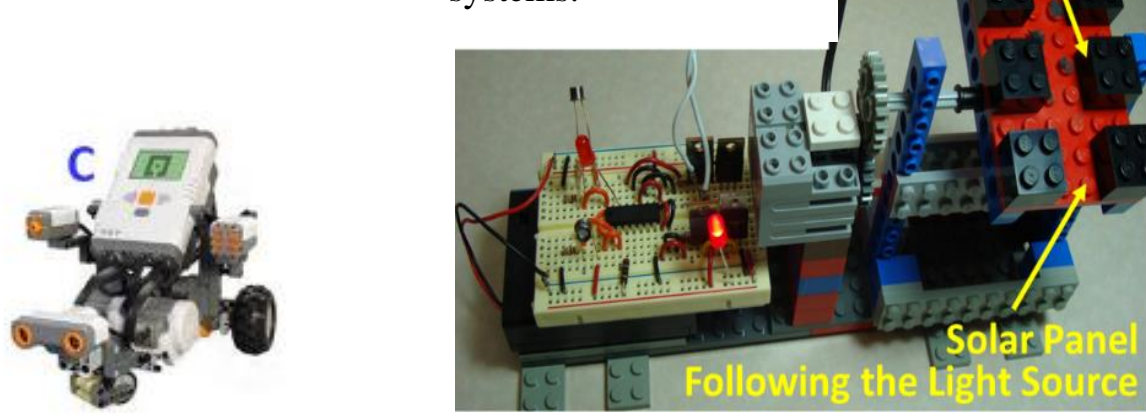

Fig. 35 Inter-robot

wireless

communication used

to address bullying.

As shown in Fig. 34 motion sensors, attached to the fastest moving parts of a dancer's body, switch (on and off) light and sound devices. This visualizes the dancing one hand and checks the health of dancer's body parts. The health monitoring part may increase the dancer's interest in technology. How to explain the technologies to dancers and other social artists. Thus, TAD can help learn technologies across many disciplines. For example, dancing and music majors may develop interest in TAD.

Technology Assisted Psychology (TAP): Inter-robot wireless communication used to address bullying; b-bully, nvictim \& c-bystander robots. Fig. 35 shows different options to study b, $\mathrm{n}$ and $\mathrm{c}$ and show this to any civilized gathering conveying messages without referring to any human being. An extension of this concept to other areas such as bullying of females in some cultures, microaggression [37] and minority issues.

Technology Assisted Smart Solar-systems (TASS): Fig. 36 shows a LEGO based learning system that demonstrates how a solar system can follow the sun or any other source of light. Such system, optimizing the energy generation, are needed for zero-energy buildings that take no energy from outside. A similar system can optimize the wind energy generation.

\section{ACKNOWLEDGEMENTS}

A part of this research was supported by NSF Engineering Research Center for Wireless Integrated Micro Systems (WIMS) during 2000-2010.

\section{REFERENCES}

[1] M. Lipman, Thinking in Education. New York: Cambridge Univ. Press, 1991.

[2] P. C. Blumenfeld, R. W. Marx, H. Patrick, J. S. Krajcik, and E. Soloway, “Teaching for understanding," in International Handbook of Teachers and Teaching, B. J. Biddle, T. L. Good, and I. F. Goodson, Eds. Dordrecht, The Netherlands: Kluwer, 1997, pp. 819-878.

[3] Cognition \& Technology Group at Vanderbilt, "The jasper series as an example of anchored instruction: Theory, program description, and assessment data,” Educ. Psychol., vol. 27, no. 3, pp. 291-315, 1992.

[4] J. S. Krajcik, P. C. Blumenfeld, R. W. Marx, K. M. Bass, J. Fredricks, and E. Soloway, "Inquiry in project based science classrooms: Initial attempts by middle school students," J. Learn. Sci., vol. 7, no. 3-4, pp. 313-350, 1998.

[5] D. E. Penner, R. Lehrer, and L. Schauble, "From physical models to biomechanics: A design-based modeling approach," J. Learn. Sci., vol. 7, no. 3-4, pp. 429-449, 1998.

[6] N. B. Songer, "Exploring learning opportunities in coordinated network-enhanced classrooms: A case of kids as global scientists," J. Learn. Sci., vol. 5, pp. 297-328, 1996

[7] D. Fortus, R. C. Dershimer, J. Krajcik, R. W. Marx, and R. Mamlok-Naaman, "Design based science and student learning,", J. Res. Sci. Teach., vol. 41, pp. 1081-1110, 2004

[8] P. Roberts, "The place of design in technology education," in Innovations in Science and Technology Education, D. Layton, Ed. New York: UNESCO, 1995, pp. 27-38.

[9] M. Davis, P. Hawley, B. McMullan, and G. Spilka, Design as a Catalyst for Learning. Alexandria, VA: Assoc. Supervision Curriculum Dev., 1997.

[10] E. L. Chiapetta, T. R. Koballa, Jr., and A. T. Collette, Science Instruction in the Middle and Secondary Schools, 5th ed. Upper Saddle River, NJ: Prentice-Hall, 2002 


\title{
International Journal of Advanced Research in Computer and Communication Engineering
}

\author{
Vol. 9, Issue 6, June 2020
}

[11] J. L. Kolodner, D. Crismond, J. Gray, J. K. Holbrook, and S. Puntambekar, "Learning by design from theory to practice”, Int. Conf. Learn. Sci., pp. 16-22, Atlanta, GA, 1998.

[12] D. M. Aslam, "Technology Assisted Science, Engineering and Mathematics (TASEM) education at all levels using K-Ph.D. concept," in Proc. ASEE Annu. Conf., Chicago, IL, 2006, p. 92

[13] D.M. Aslam, A. Abu-Ageel, M. Alfatlawi, M.W. Varney, C.M. Thompson \& S.K. Aslam, "Passive Maple-seed Robotic Fliers for Education, Research and Entrepreneurship", J. Edu Training Studies, vol. 2, 206-216, 2014; http://redfame.com/journal/index.php/jets/article/view/318/308

[14] M.Varney, A. Janoudi, D.M. Aslam, D. Graham, "Building Young Engineers: TASEM for Third Graders in Woodcreek Magnet Elementary School", IEEE Trans. Edu, Issue 99, 2012. 28 citations, 2018

[15] Multi university NSF Engineering Research Center for WIMS, 2000- 2010.

[16] Ho-Yin Chan, Dean M. Aslam, James Wiler and Brendan Casey, "A novel diamond micro probe for Neuro-chemical and -electrical recording in neural prosthesis", IEEE J. Micro Electro Mech. Sys, Vol. 18, pp. 511-521, 2009.

[17] N. Sepulveda, J. Lu, D. M. Aslam and J. Sullivan, "High-Performance Polycrystalline Diamond Micro- and Nano-resonators", IEEE J. Micro Electro Mech. Sys, Vol. 17, No. 2, pp. 473-482, April 2008.

[18] Z. Cao and D.M. Aslam, "Fabrication technology for single-material MEMS using polycrystalline diamond", Diamond and Related Materials, Volume 19, Issue 10, 1263-1272, 2010.

[19] https://en.wikipedia.org/wiki/Atomic_force_microscopy

[20] Elizabeth Pennisi, "Synthetic Genome Brings New Life to Bacterium”, Science, 5981, vol. 328, 958-959, 2010; DOI: 10.1126/science.328.5981.958

[21] Daniel G Gibson1, Lei Young1, Ray-Yuan Chuang, J Craig Venter, Clyde A Hutchison III and Hamilton O Smith, "Enzymatic assembly of DNA molecules up to several hundred kilobases", Nature Methods, Vol.6 (5), 2009; ; DOI:10.1038/NMETH.1318

[22] Silicon Angle, Nov. $5^{\text {th }}$; http://siliconangle.com/blog/2015/11/05/bizarre-brain-power-smart-homes-prosthetic-limbs-and-more/

[23] IEEE Institute; 10-6-15: Mind-Controlled Technology Could Make Homes Smarter; http://theinstitute.ieee.org/technology-focus/technologytopic/mindcontrolled-technology-could-make-homes-smarter

[24] Science Alert; June 2, 2015; http://www.sciencealert.com/this-professor-thinks-he-has-the-key-to-controlling-your-home-with-your-mind

[25] Business Insider, May 31, 2015; http:// www.businessinsider.com/using-mind-control-to-command-the-smarthome-2015-5

[26] D.M. Aslam and G.D. Dangi, "Design, Fabrication and Testing of a Smart Robotic Foot", Robotics and Autonomous Sys., vol. 51 (2,3), $207-$ 214(2005).

[27] L. Tummala, R. Mukherjee, N. Xi, D.M. Aslam, H. Dulimarta, J. Xiao, M. Minor and G. Dangi, "Climbing the Walls", IEEE Robot. Autom. Magazine, vol. 9, 10-19 (2002).

[28] M. M. Maharbiz, H. Sato, "Cyborg Beetles; tiny flying robots that are part machine and part insect may one day save lives in wars and disasters", Scientific American, Vol. 303 (6), 94-99 (2010).

[29] Y. Feng, B. Yang, Y. Jiang and X. Zheng, "Research on Key Techniques of Insect Flapping Onset Control Based on Electrical Stimulation", Sensors, MDPI, 20, 239 (2020); doi:10.3390/s20010239 www.mdpi.com/journal/sensors

[30] https://www.sciencedaily.com/releases/2019/02/190213124347.htm.

[31] Barbara A Cohn, Piera M Cirillo, Mary Beth Terry. DDT and Breast Cancer: Prospective Study of Induction Time and Susceptibility Windows. JNCI: Journal of the National Cancer Institute, 2019; DOI: 10.1093/jnci/djy198

[32] L. Feng, J. Zhu and Z. Wang, "Biological Functionalization of Conjugated Polymer Nanoparticles for Targeted Imaging and Photodynamic Killing of Tumor Cells", ACS Appl. Mater. Interfaces, 30, 19364-19370 (2016); https://doi.org/10.1021/acsami.6b06642

[33] Daniel Hauser et al., "Polydopamine/Transferrin Hybrid Nanoparticles for Targeted Cell-Killing", Nanomaterials, 8,1065 (2018); doi:10.3390/nano8121065 www.mdpi.com/journal/nanomaterials

[34] D.M. Aslam, "Intriguing Aspects of New Scientific Mind Model as EEG Data Based Algorithm", IJARCCE, Vol. 8 (12), 79-86, 2019; https://ijarcce.com/papers/intriguing-aspects-of-new-scientific-mind-model-as-eeg-data-based-algorithm/; DOI: $10.17148 /$ IJARCCE.2019.81217.

[35] D.M. Aslam, "Mind as EEG Data Based Algorithm is Decision Maker not Brain", Science e-letter, October 4, 2019: https://science.sciencemag.org/content/313/5787/684/tab-e-letters

[36] https://www.health.harvard.edu/staying-healthy/how-to-boost-your-immune-system

[37] Derald Wing Sue et al., "Racial Microaggressions in Everyday Life Implications for Clinical Practice", American Psychologist, Vol. 62 (4), 271286 (2007). DOI: 10.1037/0003-066X.62.4.2 